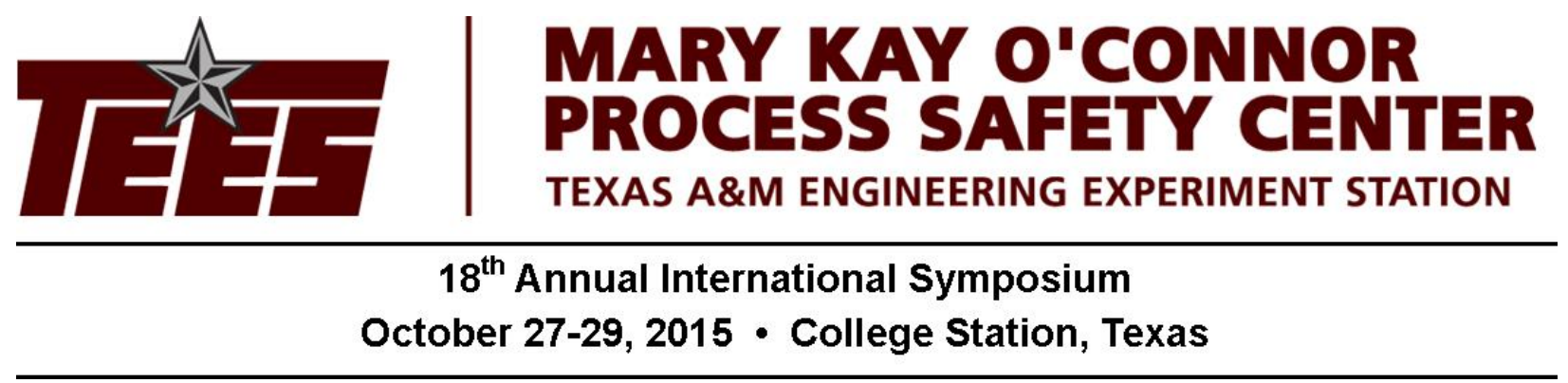

\title{
Where to Begin -A Parametric Study for Vapor Barriers at LNG Export Facilities
}

\author{
B. Hendrickson, C. Marsegan, F. Gavelli \\ GexCon US - Bethesda, MD
}

\begin{abstract}
Vapor barriers are widely used to contain the release of flammable mixtures in LNG facilities in the United States. The computational fluid dynamics (CFD) modeling tool FLACS has been validated and accepted for detailed consequence modeling of flammable vapor dispersion scenarios and includes capabilities to assess the impact of vapor barriers at varying heights and locations. While every plant design is unique and the optimization of vapor barriers often requires several iterations, guidance on where to begin is often limited. This paper will detail a parametric study on vapor barrier height and placement for different release rates to establish a basis for beginning a vapor barrier design.
\end{abstract}

\section{Introduction}

The siting requirements for LNG facilities vary depending on how the natural gas is transported to and from the facility. Many LNG facilities are connected to a natural gas pipeline that requires compliance with Title 49 of the Code of Federal Regulations (CFR) Part 193, Liquefied Natural Gas Facilities: Federal Safety Standards. In addition to thermal radiation requirements for LNG, the regulations specify that provisions must be made to minimize the possibility of a flammable mixture of vapors from a specified release reaching a property line that can be built upon and that would result in a distinct hazard [1]. The footprint of the flammable gas cloud (to a concentration of one-half of the lower flammability limit, or $1 / 2 \mathrm{LFL}$ ) is referred to as an exclusion zone. Passive mitigation measures can be employed to reduce these exclusion zones.

Vapor barriers are commonly used to control the dispersion of flammable vapor clouds which form in the event of an accidental release, therefore reducing the overall size of the flammable cloud footprint and the amount of land the facility owner must control in order to meet the facility siting regulations. Vapor barriers vary in height and permeability and must be constructed to sustain $150 \mathrm{mph}$ wind loads. Vapor barriers may be as simple as a chain-link fence with slats, which would be permeable as the slats do not cover $100 \%$ of the fence's surface area or as robust as masonry walls.

The type of vapor barriers needed for an LNG export facility will depend on the size of the accidental releases that must be evaluated and the distance between the release point and the nearest property line. This paper will describe a parametric study in which the CFD modeling tool FLACS was used to evaluate the effectiveness of vapor barriers placed at various heights 
and distances from the release point against common release rates for an LNG export facility. Vapor barrier heights in this study will range from 10 to $30 \mathrm{ft}$ high and will be located 150 to $1000 \mathrm{ft}$ downstream of the release point. Both LNG (modeled as pure methane) and propane will be assessed to include the impact of molecular weight on vapor barrier interaction. The results of this study will provide a basis for preliminary vapor barrier design based on the release scenarios and layout of a particular facility.

\section{FLACS Overview}

FLACS is a CFD tool being developed since 1980 for the simulation of gas dispersion and vapor cloud explosion scenarios. FLACS is capable of modeling gas and aerosol releases, dispersion of vapors, ventilation in structures, and ignition of flammable fuel-air mixtures to evaluate the flame front progression and overpressures due to explosions; all these physical phenomena are simulated in a full three-dimensional domain and take into account the interaction between the fluid flow and obstacles, obstructions and topography.

FLACS solves the compressible Reynolds-Averaged Navier-Stokes (RANS) equations on a 3D Cartesian grid using a finite volume method [2] [3]. The conservation equations for mass, impulse, enthalpy, turbulence and species, closed by the ideal gas law are included. The RANS equations are closed using the $k-\varepsilon$ turbulence model with the standard set of constants taken from Launder \& Spalding [4], as described by Harlow and Nakayama [3]. The SIMPLE pressure correction method is applied [5], and extended for compressible flows with source terms for the compression work in the enthalpy equation. The FLACS solver uses a semi-implicit method, where spatial flux terms are treated explicitly; the solver is second order accurate in space and first order accurate in time.

Since even small objects can have a significant impact on gas dispersion and - even more so - on flame acceleration, the accurate representation of the 3D geometry has always been a focal point in the development of FLACS. A so-called "distributed porosity concept" [2] was developed to allow the efficient handling of complex geometries using a Cartesian grid: large objects and walls are represented on-grid, and smaller objects are represented subgrid. Each grid volume is assigned porosity values based on the congestion contained within the cell, and these porosities (both area and volume) adjust the RANS equations. This modification allows the effect of small obstacles to be accounted for, while maintaining reasonable simulation times: sub-grid objects contribute to flow resistance, turbulence generation and flame folding in the simulation [6]. In this way, objects (cylinders or prisms) as small as 1/64 of the control volume size can be accounted for.

Buoyancy effects for atmospheric gas dispersion are taken into account in the turbulent equations. The atmospheric boundary layer is modelled by forcing profiles for the velocity, temperature and the turbulence parameters on inlet boundaries. At inflow boundaries, vertical profiles of wind speed and direction, temperature, turbulent kinetic energy and eddy dissipation rate are imposed according to the atmospheric stability class or to the Monin-Obukhov and surface roughness lengths. The vapor dispersion capabilities of FLACS have been validated against several field experiments involving both dense gas and passive gas releases, including $\mathrm{CO}_{2}$ releases in an array of flat billboard-shaped obstructions (the Kit Fox experiments) and tracer gas releases in an array of rectangular storage containers in the Mock Urban Setting Test (MUST) experiments [7]. FLACS was also validated against the 33 experimental tests included in the Model Validation Database for LNG vapor dispersion models [8]. 


\section{Release Scenarios}

As part of the facility siting requirements under federal jurisdiction, liquid spills into trenches and sumps must be evaluated as well as flashing and jetting releases from pipe failures. Vapor cloud formation from a flashing and jetting release tends to be significantly larger than that from vaporization from a liquid spill of similar size, due to the delayed evaporation from the liquid pool; therefore, flashing and jetting releases are frequently the governing scenarios for determining exclusion zones. Vapor generation from liquid evaporation will be compared to that of a flashing release in the Results section.

The size of the flashing and jetting release to be evaluated is based on guidance from the U.S. Department of Transportation Pipeline and Hazardous Materials Safety Administration (PHMSA) [9]. . For any given pipe, a failure rate is calculated based on the pipe diameter and total length, which determines the maximum credible hole size to be evaluated for a flashing release. The threshold for a credible release scenario is set to $3 \times 10^{-5}$ failures per year. The resulting release scenario is referred to as a single accidental leakage source (SALS).

The following example shows a basic SALS determination for a 30-in LNG transfer line that is 3,000 ft (914 m) long:

Table 1. Failure rates for piping between 20-in and 40-in [9].

\begin{tabular}{|cc|}
\hline $\begin{array}{c}\text { Type of Failure } \\
\text { (hole size) }\end{array}$ & $\begin{array}{c}\text { Failure Rate } \\
\text { (per year of operation) }\end{array}$ \\
\hline $\begin{array}{c}\text { Guillotine failure } \\
\text { 1/3 Diameter }\end{array}$ & $2 \times 10^{-8}$ per meter of piping \\
\hline 2-in Diameter & $1 \times 10^{-7}$ per meter of piping \\
\hline 1-in Diameter & $2 \times 10^{-7}$ per meter of piping \\
\hline & $4 \times 10^{-7}$ per meter of piping \\
\hline
\end{tabular}

Guillotine failure (full diameter):

$$
2 \times 10^{-8} \frac{\text { failures }}{m \cdot y r} \times 914 m=1.8 \times 10^{-5} \frac{\text { failures }}{y r}<3 \times 10^{-5} \frac{\text { failures }}{y r} \therefore \text { not credible }
$$

1/3 Diameter hole:

$$
1 \times 10^{-7} \frac{\text { failures }}{m \cdot y r} \times 914 m=9.1 \times 10^{-5} \frac{\text { failures }}{y r}>3 \times 10^{-5} \frac{\text { failures }}{y r} \therefore \text { credible }
$$

The largest credible hole size for this 30-in transfer line has a diameter of 10-in. It is important to note that all hole sizes less than 10 -in are also credible. Depending on the process conditions, a smaller hole size may actually result in less liquid rainout (liquid that does not vaporize upon exiting the pipe and falls to the ground forming a pool) and longer dispersion distances. 
The largest hole sizes often occur on large LNG transfer lines, such as the rundown line from the liquefaction trains to the storage tank and LNG loading (or unloading) lines between the LNG storage tank and the ship loading (or unloading) dock. LNG facilities often include truck loading operations and, even though the lines associated with truck loading are often small (e.g., 2 or 3-in diameter), the truck loading area is usually located close to property boundaries and therefore a release from this location could extend offsite. Heavier hydrocarbons, such as propane, are also present at LNG liquefaction facilities and serve as part of the liquefaction process. Propane releases are often evaluated in both the liquefaction process units and vessels in a refrigerant storage area. Accordingly, five scenarios were identified for evaluation as part of this study; the scenarios are listed in Table 2 and the FLACS 3D geometries used for each scenario are shown in Figure 1 through Figure 6.

Table 2. Single accidental leakage sources considered for the barrier study.

\begin{tabular}{|lcccccc|}
$\begin{array}{c}\text { Scenario } \\
\text { ID }\end{array}$ & Description & $\begin{array}{c}\text { Pressure } \\
\text { [psig] }\end{array}$ & $\begin{array}{c}\text { Temp. } \\
{\left[{ }^{0} \mathbf{F}\right]}\end{array}$ & $\begin{array}{c}\text { Flow Rate } \\
\text { [gpm] }\end{array}$ & $\begin{array}{c}\text { Hole Size } \\
{[\text { [in.] }}\end{array}$ & $\begin{array}{c}\text { Rainout } \\
{[\%]}\end{array}$ \\
\hline LNG-1 & LNG truck loading & 50 & -265 & 800 & 2 & 0 \\
\hline LNG-2 & LNG rundown line & 70 & -265 & 4,000 & 4 & 0 \\
\hline LNG-3 & LNG loading line & 40 & -250 & 17,500 & 10 & 57 \\
\hline PRO-1 & Propane in process area & 225 & 115 & 1,600 & 2 & 0 \\
\hline PRO-2 & Propane in storage area & 180 & 100 & 3,200 & 3 & 0 \\
\hline
\end{tabular}

Liquid rainout is common for large LNG releases and is collected into trenches which direct the liquid to a containment basin. The release conditions for the LNG loading line (scenario LNG-3) are such that the release will be divided between the initial vapor flash fraction (approximately $43 \%$ for the given system conditions) and liquid (57\%) which will rain out and be collected in the trench system. Two different geometries were built to evaluate this scenario: one with a collection sump near the release location (scenario LNG-3a shown Figure 3) and one with a trench leading off the simulation domain to represent a sump located far away from the release point (scenario LNG-3b shown in Figure 4). The simulation was also performed using only the vapor portion of the release (LNG-3c) to assess contributions of evaporation from the liquid pool on the overall footprint of the flammable cloud. 


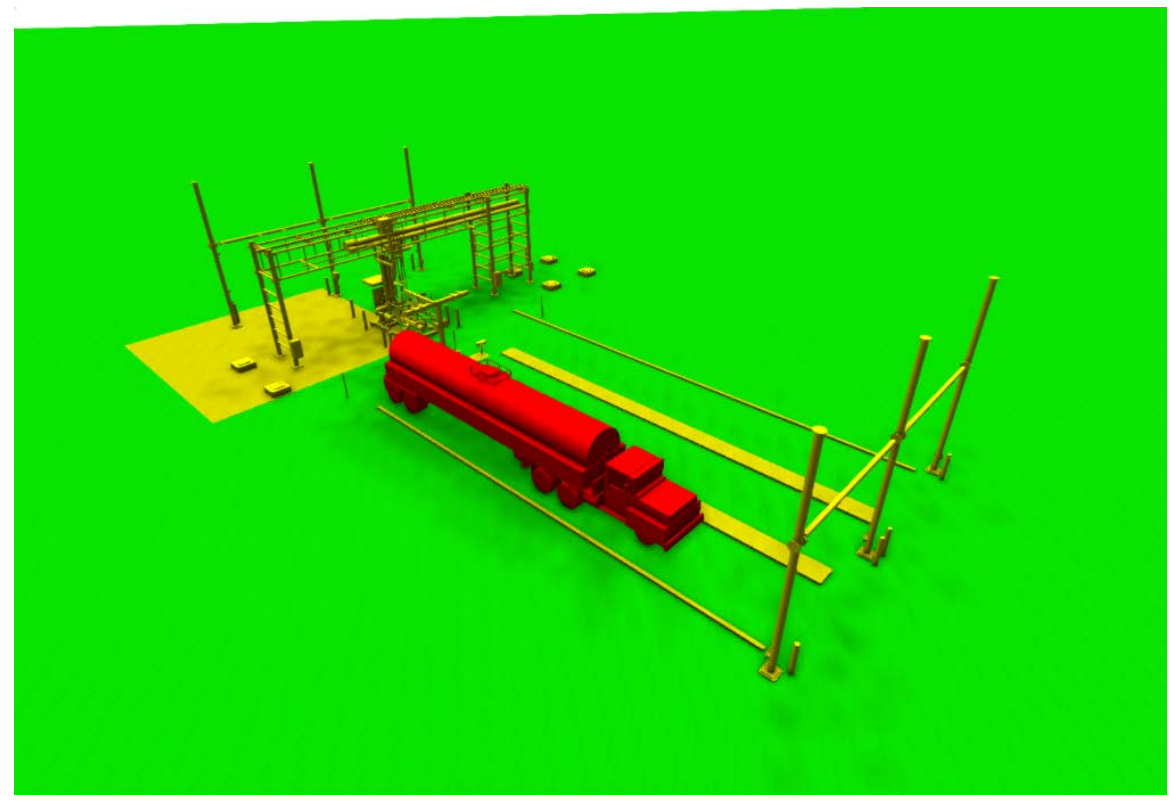

Figure 1. FLACS 3D geometry model for an LNG truck loading station (scenario LNG-1).

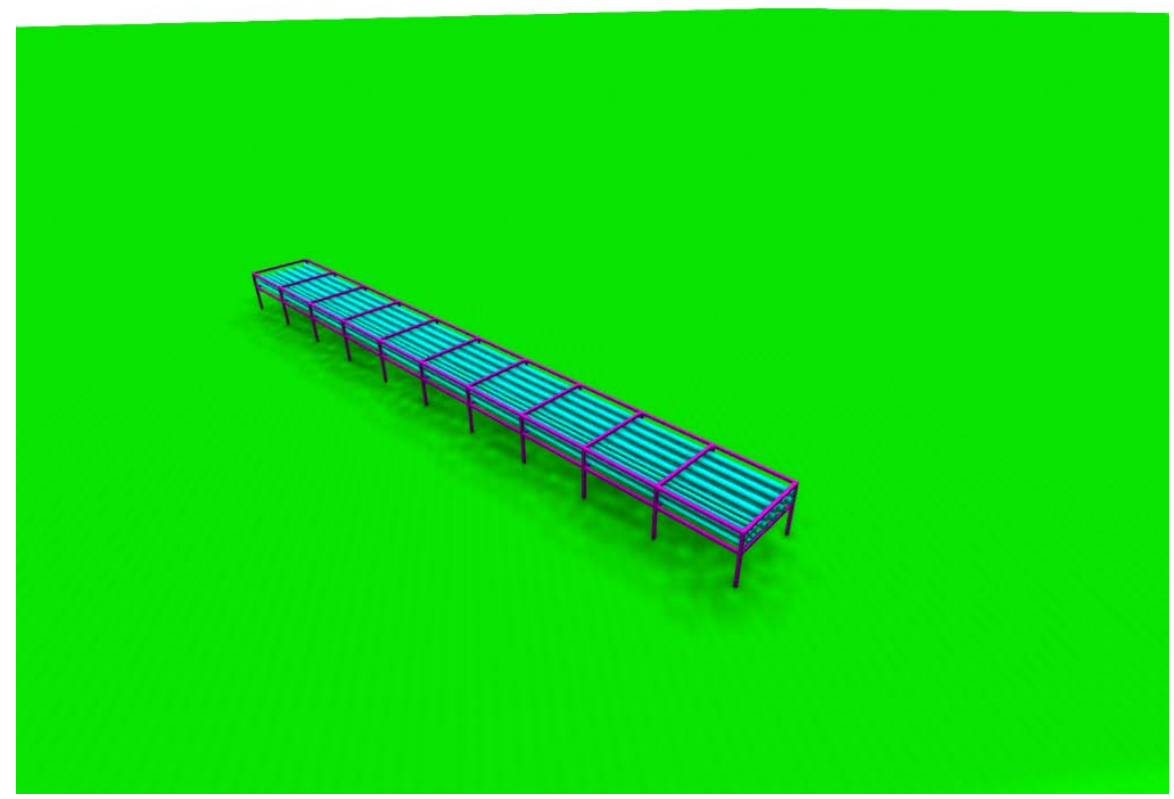

Figure 2. FLACS 3D geometry model for a congested piperack (scenario LNG-2). 


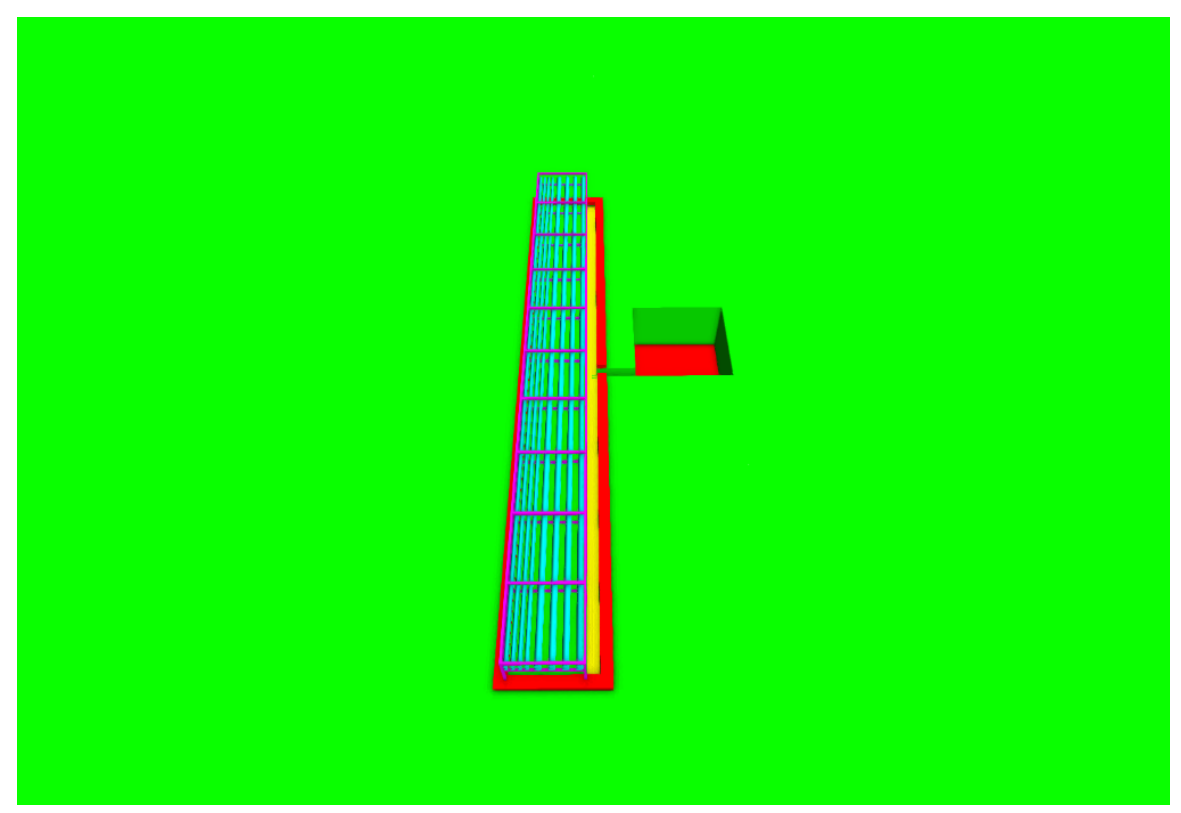

Figure 3. FLACS 3D geometry model for a curbed area around a piperack with trench (shown in yellow) leading to a nearby collection sump (scenario LNG-3a).

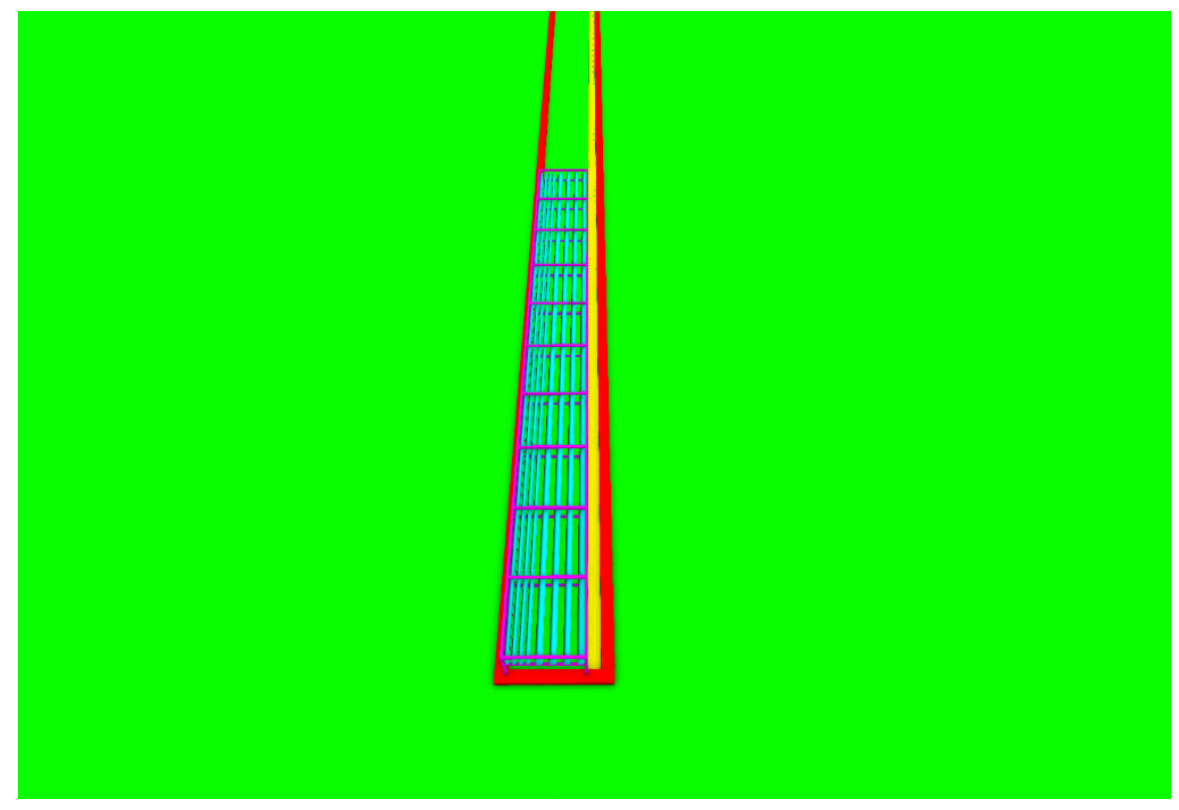

Figure 4. FLACS 3D geometry model for a curbed area around a piperack with trench (shown in yellow) leading to a remote collection sump (scenario $L N G-3 b$ and $L N G-3 c$ ). 


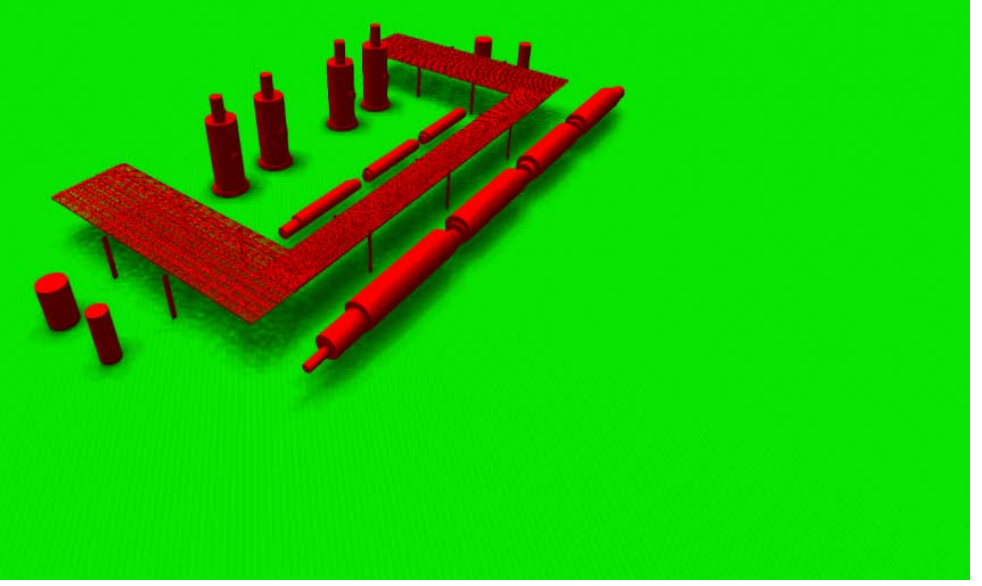

Figure 5. FLACS 3D geometry model for a propane portion of a liquefaction unit (scenario PRO-1).

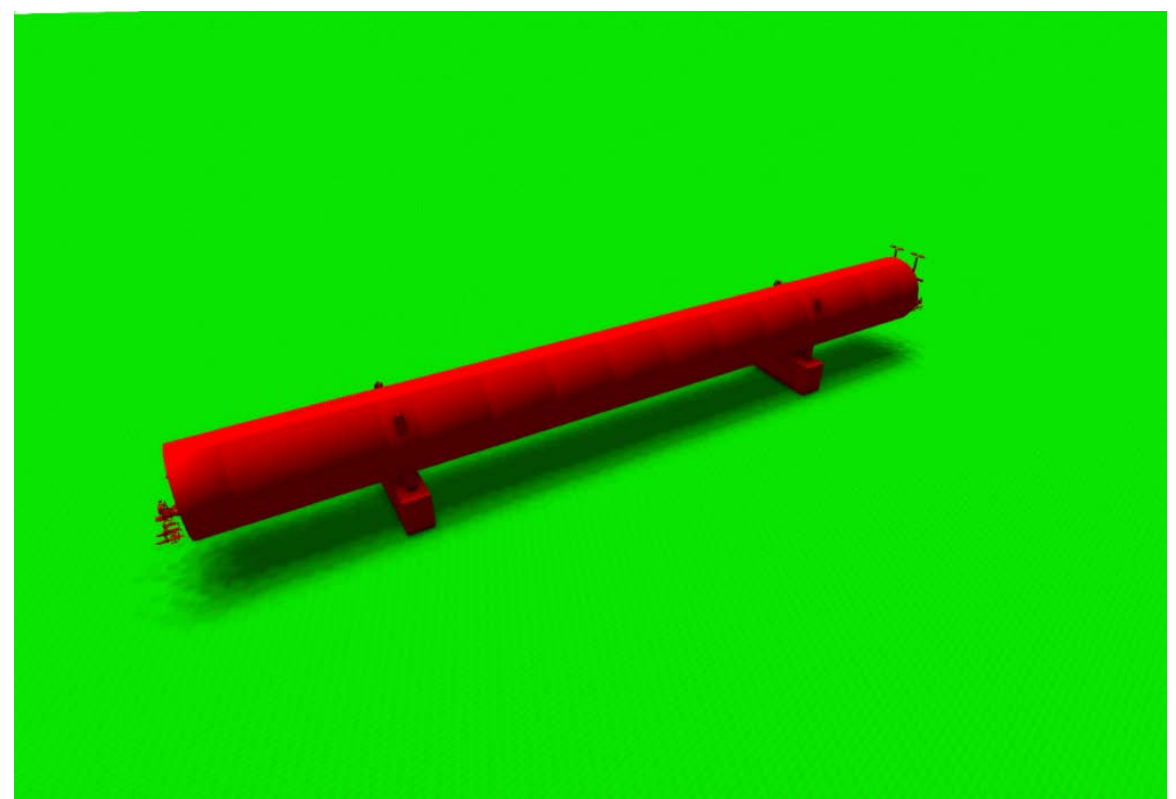

Figure 6. FLACS 3D geometry model for a propane storage vessel (scenario PRO-2).

Every scenario listed in Table 2 was modeled with the five vapor barrier configurations listed in Table 3. The "Open field" scenario does not include any barriers and serves as the base case for each release. Vapor barriers can be located close to the release point to slow the momentum of the release and redirect cloud growth; this scenario is modeled as "Internal 1" with a barrier located $150 \mathrm{ft}$ from the release point. Two barriers were assessed $500 \mathrm{ft}$ from the release: "Internal 2" whose length was determined by the width of the unmitigated cloud and represents a 
barrier placed within the facility intended to slow and redirect the cloud before reaching the property line, and "Property 1" which spans the entire simulation domain and is intended to represent a property line barrier. "Property 2" also spans the simulation domain, but is located $1000 \mathrm{ft}$ from the release point. Each barrier location was modeled at three different heights (10, 20 and $30 \mathrm{ft}$ ); all barriers were assumed impermeable (solid). The vapor barrier configurations are shown in Figure 7 and Figure 8.

Table 3. Vapor barrier configurations.

\begin{tabular}{|c|c|cc|}
\hline Barrier ID & $\begin{array}{c}\text { Distance from } \\
\text { the release } \\
\text { location [ft] }\end{array}$ & $\begin{array}{c}\text { Barrier } \\
\text { width }\end{array}$ & $\begin{array}{c}\text { Barrier height } \\
\text { [ft] }\end{array}$ \\
\hline Open field & - & - & - \\
\hline Internal 1 & 150 & Cloud & $10-20-30$ \\
\hline Internal 2 & 500 & Cloud & $10-20-30$ \\
\hline Property 1 & 500 & Domain & $10-20-30$ \\
\hline Property 2 & 1,000 & Domain & $10-20-30$ \\
\hline
\end{tabular}

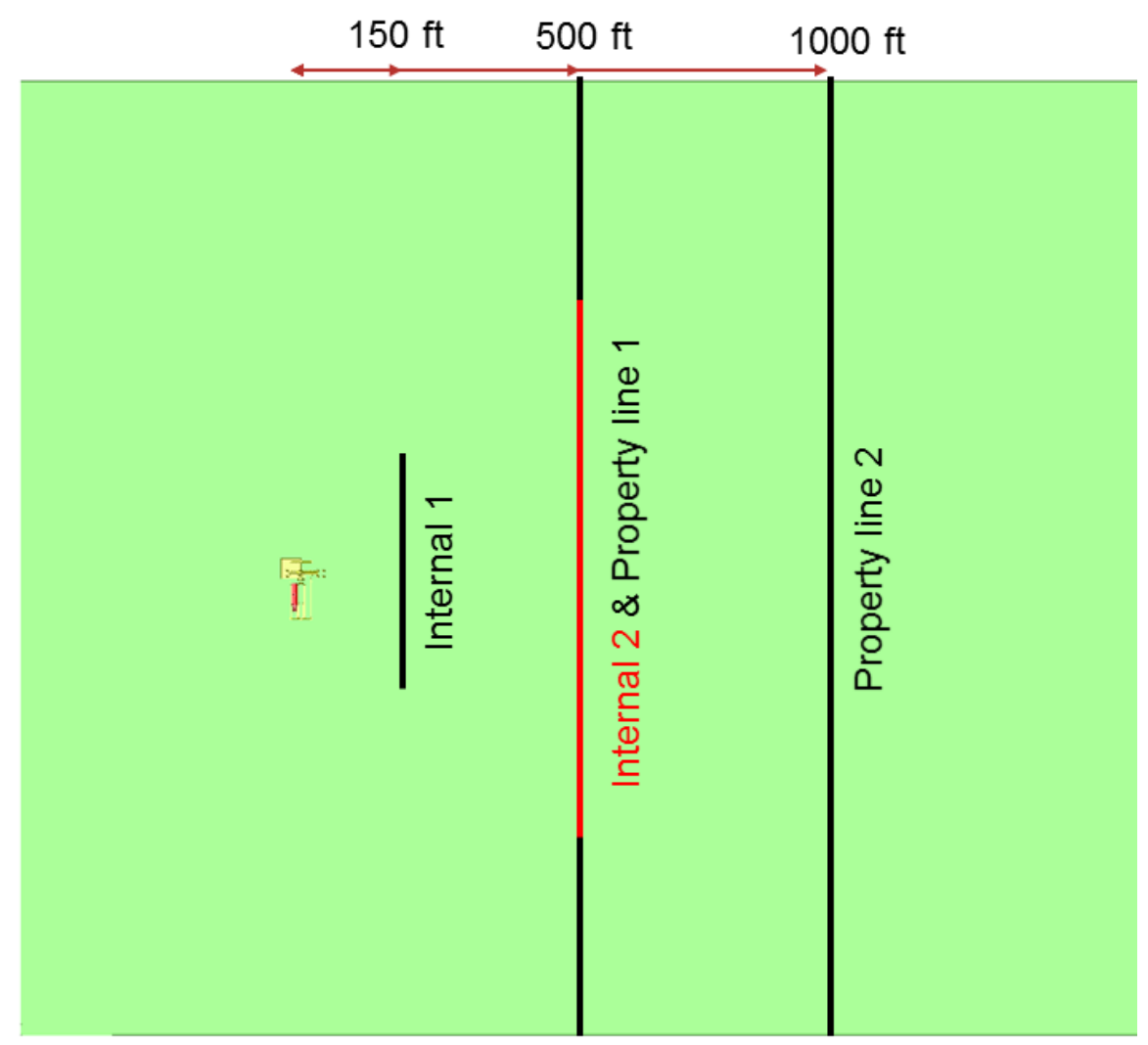

Figure 7. Diagram showing the barrier layouts using the LNG-1 geometry. 


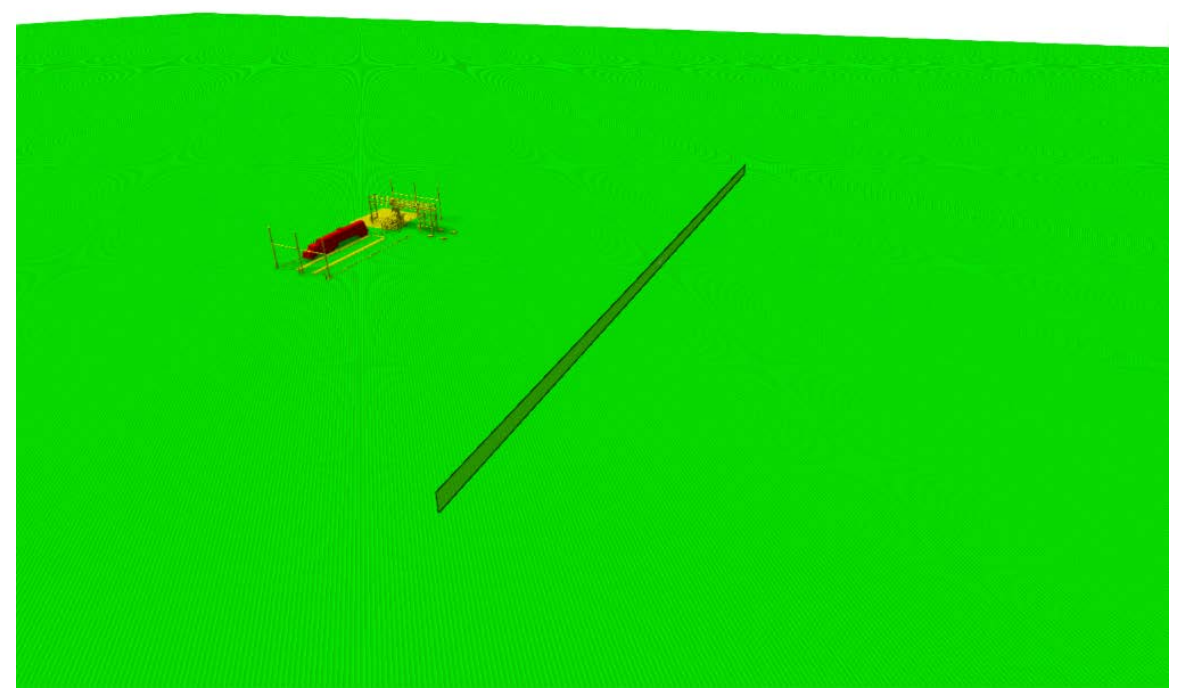

Figure 8. FLACS image showing the "Internal 1" barrier configuration for scenario LNG-1.

Ambient conditions for vapor dispersion hazard calculations are specified in federal regulations and the values used in this analysis are consistent with the requirements in 49 CFR 193: atmospheric stability (Pasquill Class) F, wind speed $=2 \mathrm{~m} / \mathrm{s}$. The ambient temperature was set to $72{ }^{\circ} \mathrm{F}$ and the effects of humidity were neglected. All simulations assumed a constant release rate for a duration of 10 minutes.

\section{Results}

The results of the FLACS vapor dispersion simulations for the releases listed in Table 2 are shown in Figure 9 through Figure 35. Each cloud is shown as the overlay of the vapor cloud footprint at each output time step (every 10 seconds). The first figure for each release shows the unmitigated vapor cloud; each subsequent figure compares a vapor barrier configuration with the open field results. An orange footprint represents the unmitigated vapor cloud, a purple, cyan, or red footprint represents the vapor cloud in the presence of a 10, 20 or $30 \mathrm{ft}$ tall barrier, respectively. The approximate release location is indicated by the base of a black arrow, which points in the direction of the release. When present, the location of the vapor barrier is identified by a black line. 


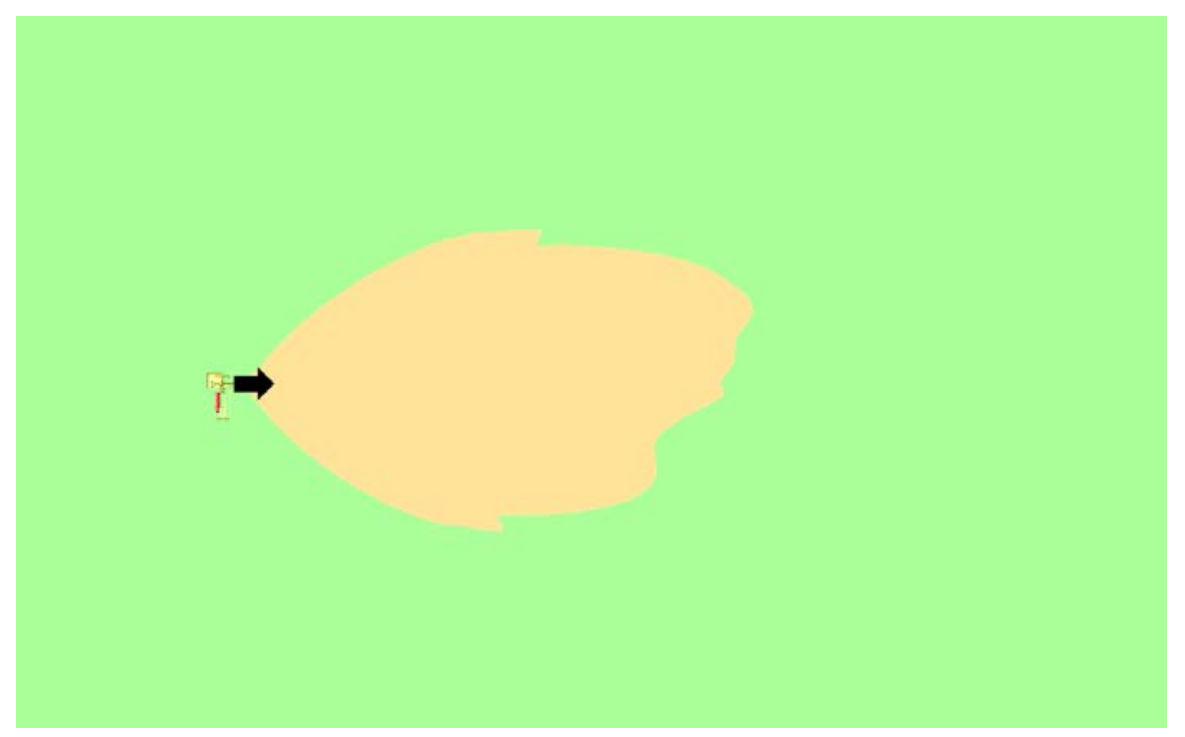

Figure 9. Vapor cloud (at or above $1 / 2-L F L$ concentration) for scenario LNG-1, “Open field" unmitigated case.

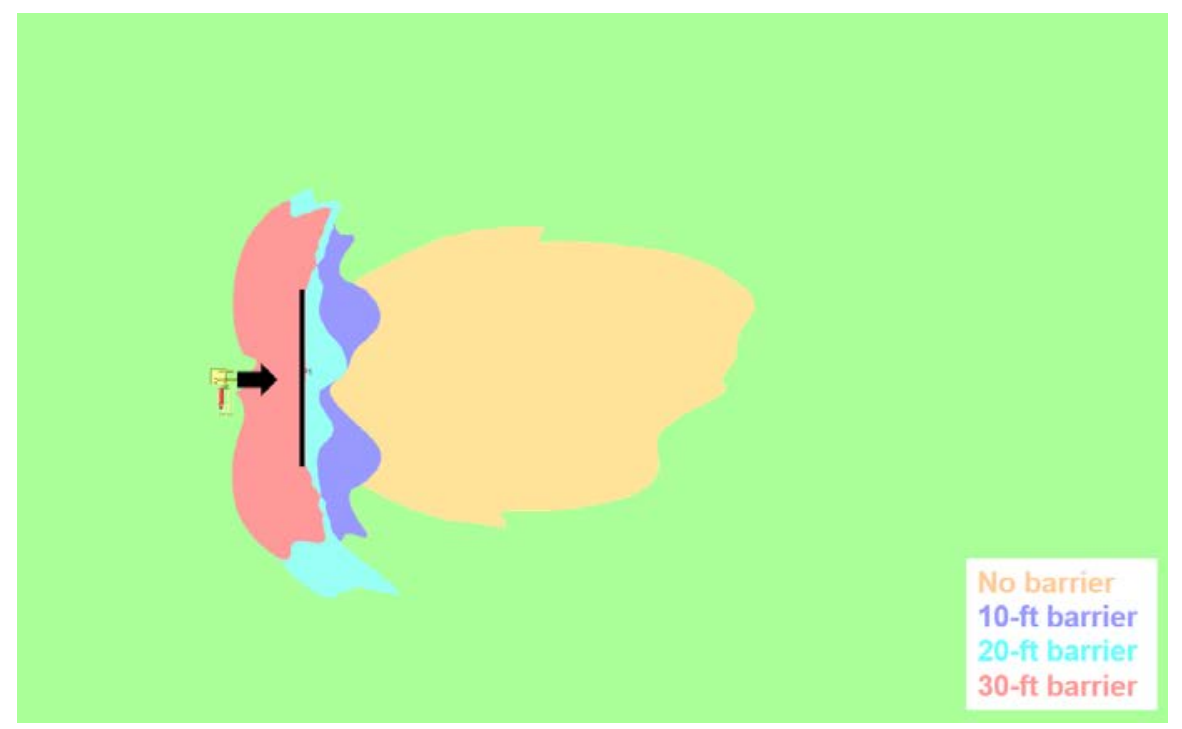

Figure 10. Vapor cloud (at or above $1 / 2-L F L$ concentration) for scenario LNG-1, "Internal 1" barrier configuration. 


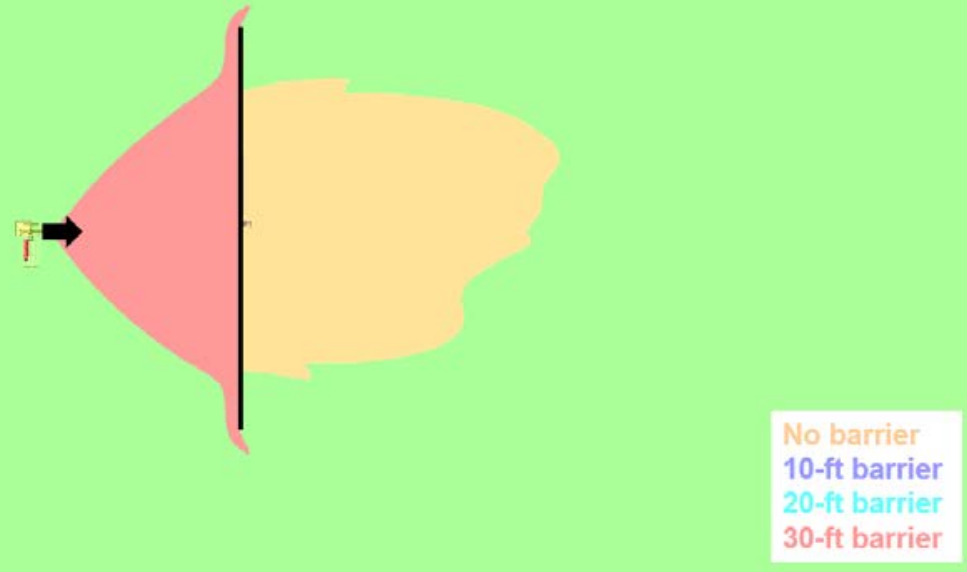

Figure 11. Vapor cloud (at or above $1 / 2-L F L$ concentration) for scenario LNG-1, "Internal 2" barrier configuration.

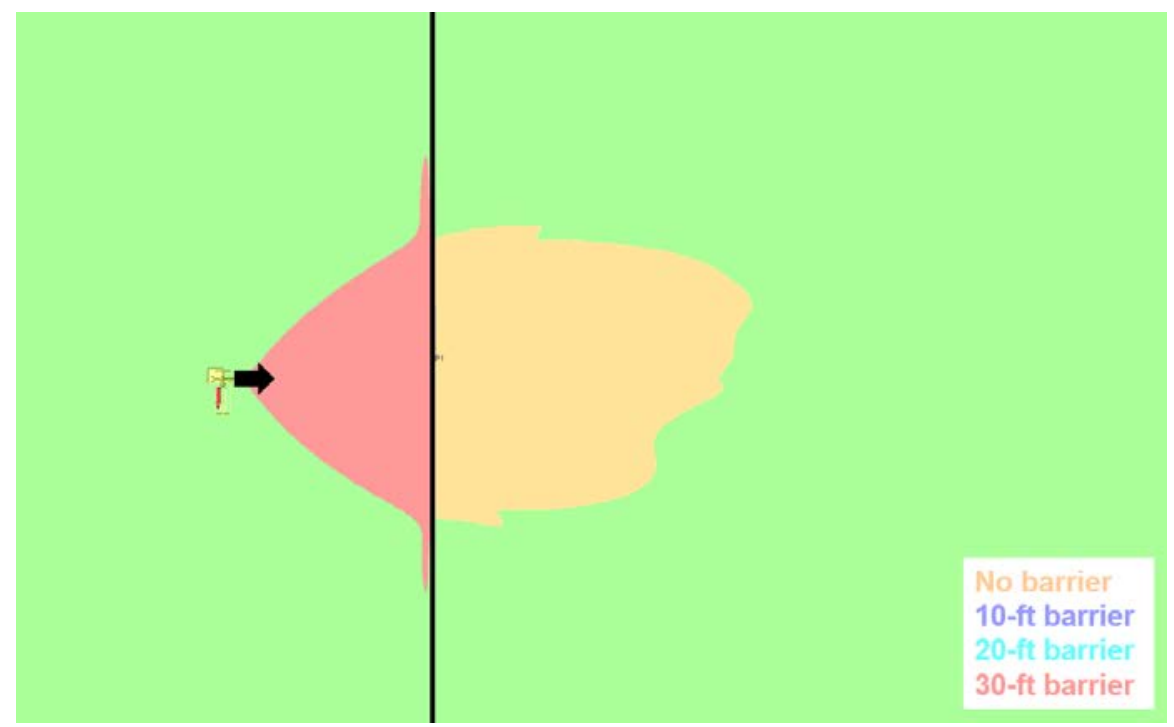

Figure 12. Vapor cloud (at or above $1 / 2-L F L$ concentration) for scenario LNG-1, "Property 1" barrier configuration. 


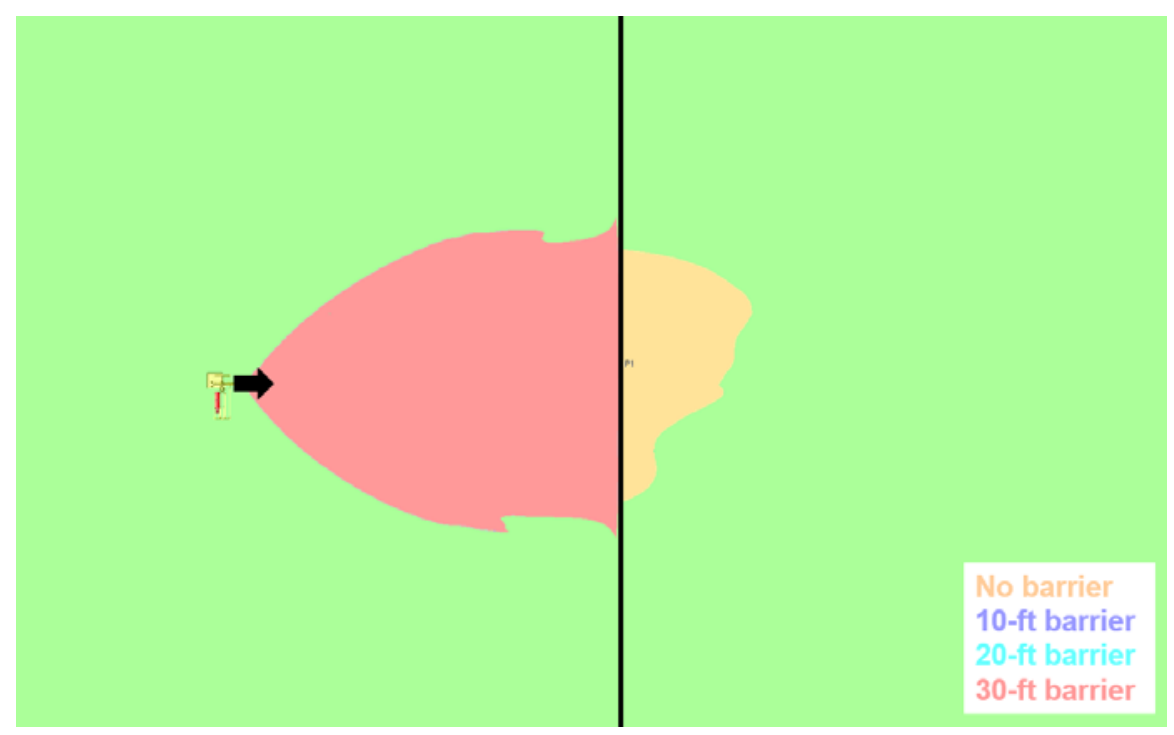

Figure 13. Vapor cloud (at or above $1 / 2-L F L$ concentration) for scenario LNG-1, "Property 2" barrier configuration.

The results show that for a relatively small flow rate, such as a release from a truck loading station, barriers located $500 \mathrm{ft}$ or more from the release point stop the cloud regardless of the barrier height. The Internal 1 barrier configuration resulted in the smallest cloud footprint and therefore offers the smallest exclusion zone by federal regulations. If this internal barrier were also intended to prevent a flammable cloud from reaching a particular ignition point on the opposite side of the barrier, a height of at least $30 \mathrm{ft}$ would be required.

Figure 14. Vapor cloud (at or above $1 / 2-L F L$ concentration) for scenario $L N G-2$, "Open field" unmitigated case. 


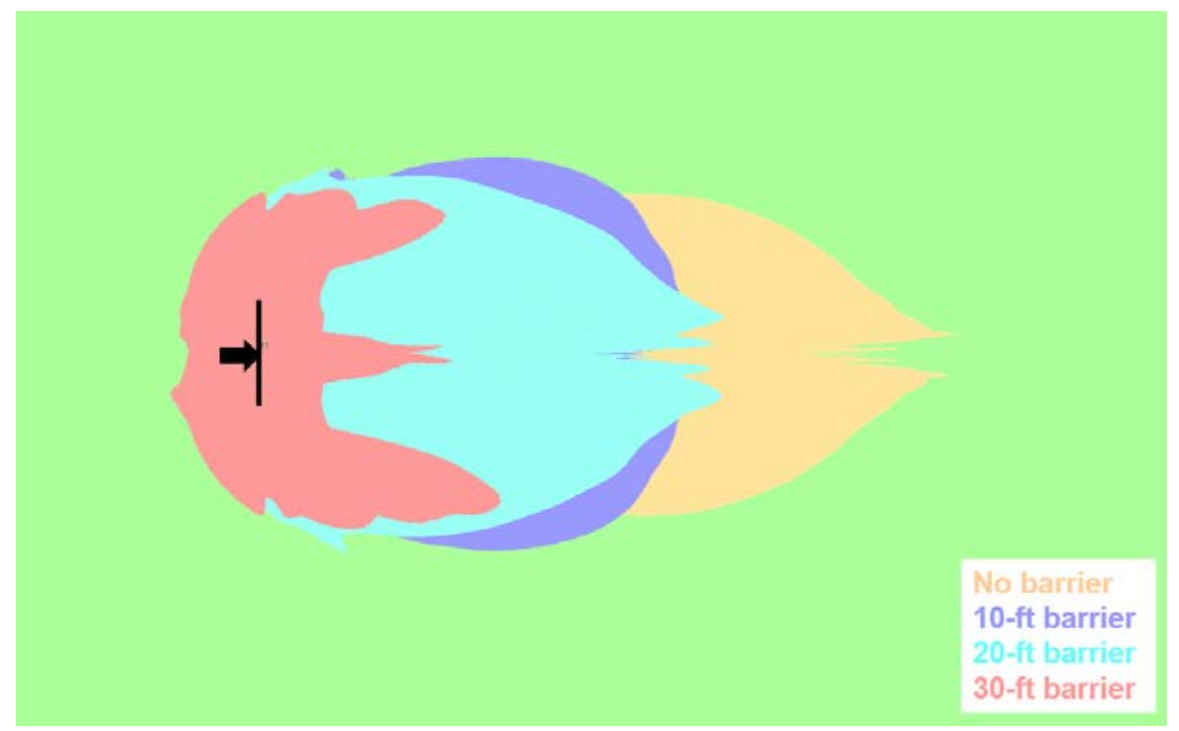

Figure 15. Vapor cloud (at or above $1 / 2-L F L$ concentration) for scenario LNG-2, "Internal 1" barrier configuration.

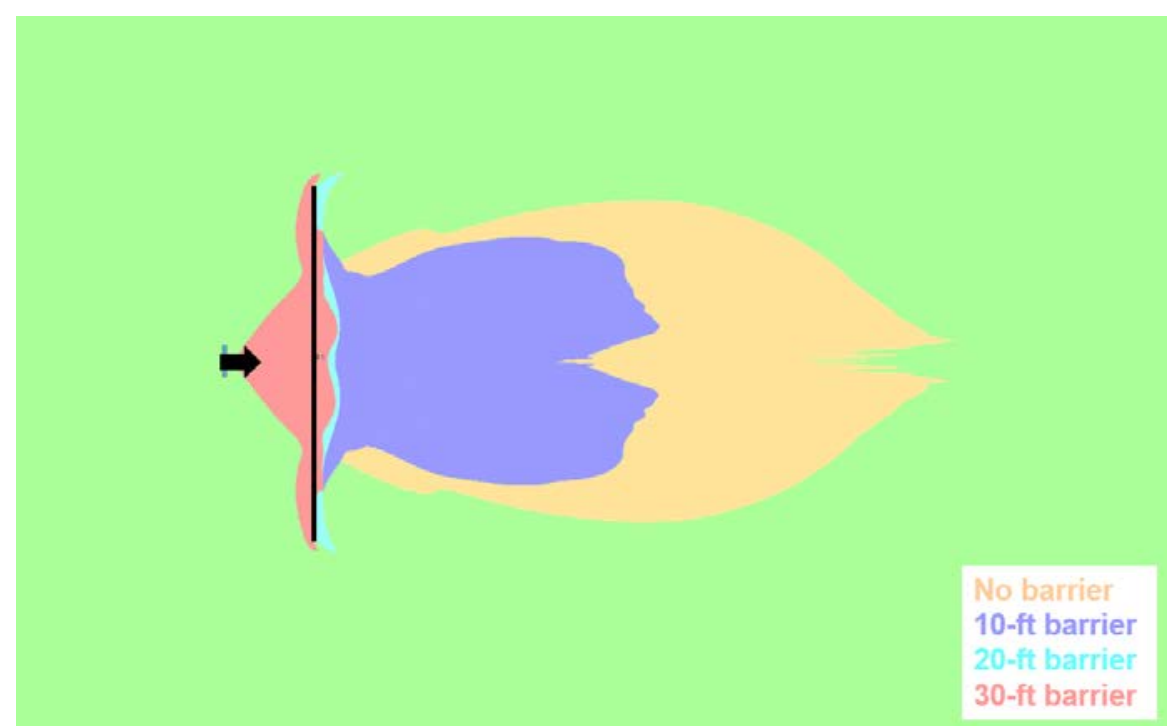

Figure 16. Vapor cloud (at or above $1 / 2-L F L$ concentration) for scenario $L N G-2$, "Internal 2" barrier configuration. 


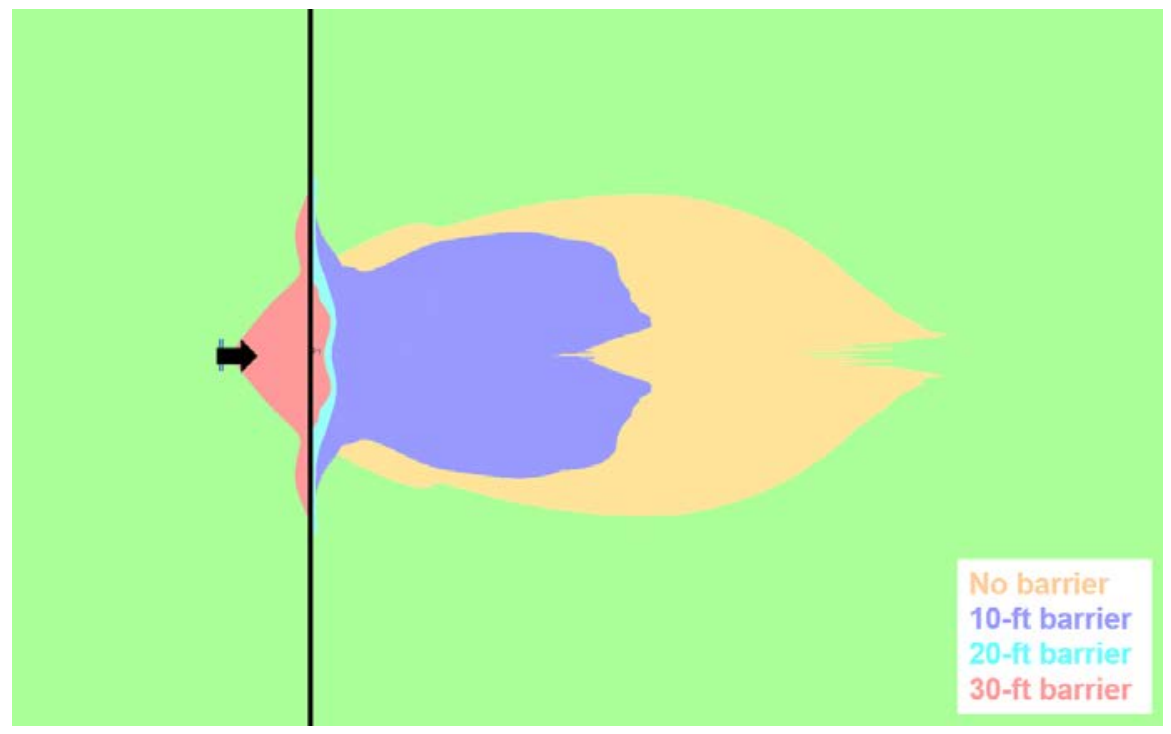

Figure 17. Vapor cloud (at or above $1 / 2-L F L$ concentration) for scenario LNG-2, "Property 1" barrier configuration.

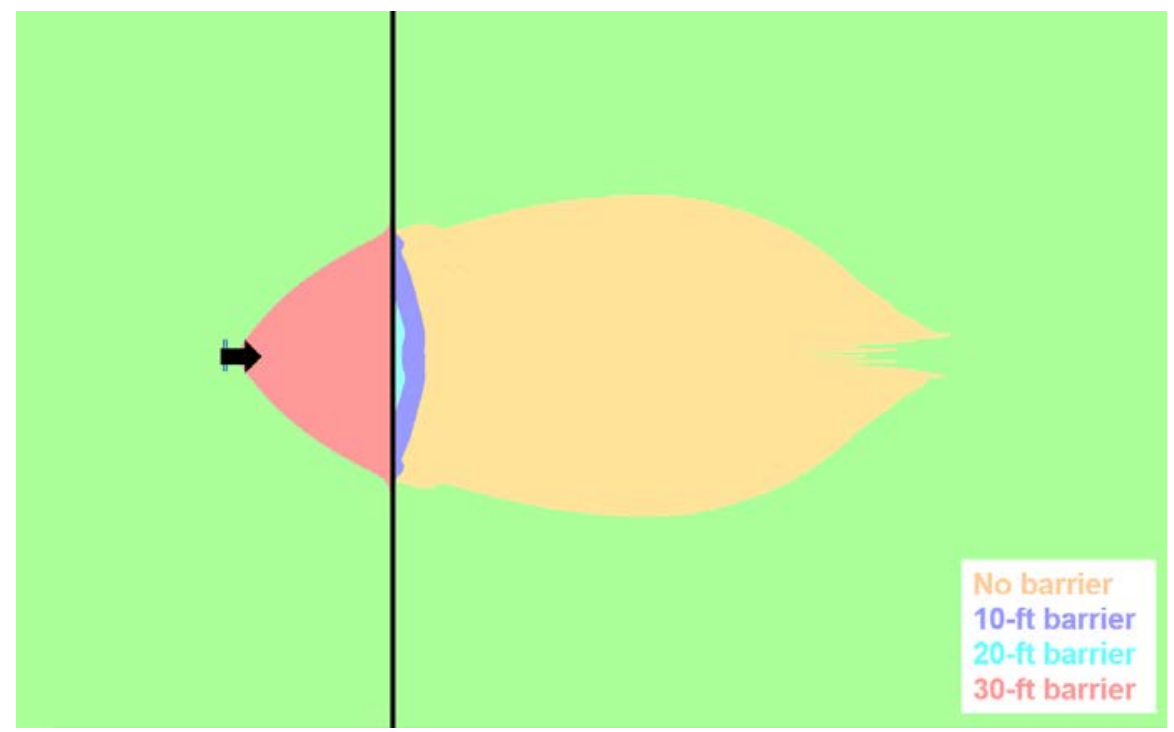

Figure 18. Vapor cloud (at or above $1 / 2-L F L$ concentration) for scenario $L N G-2$, "Property 2" barrier configuration.

Figure 15 shows that the internal barrier is less effective for a typical release from an LNG rundown line. The $30 \mathrm{ft}$ tall Internal 1 barrier reduces the furthest extent of the flammable cloud by about $60 \%$, while the lower heights perform similarly with a $30 \%$ reduction. The 20 and 30 $\mathrm{ft}$ barriers offer similar stopping power $500 \mathrm{ft}$ downstream from the release, but neither would be sufficient as a property line barrier. At $1,000 \mathrm{ft}$ only the $30 \mathrm{ft}$ barrier is capable of containing the flammable cloud. 


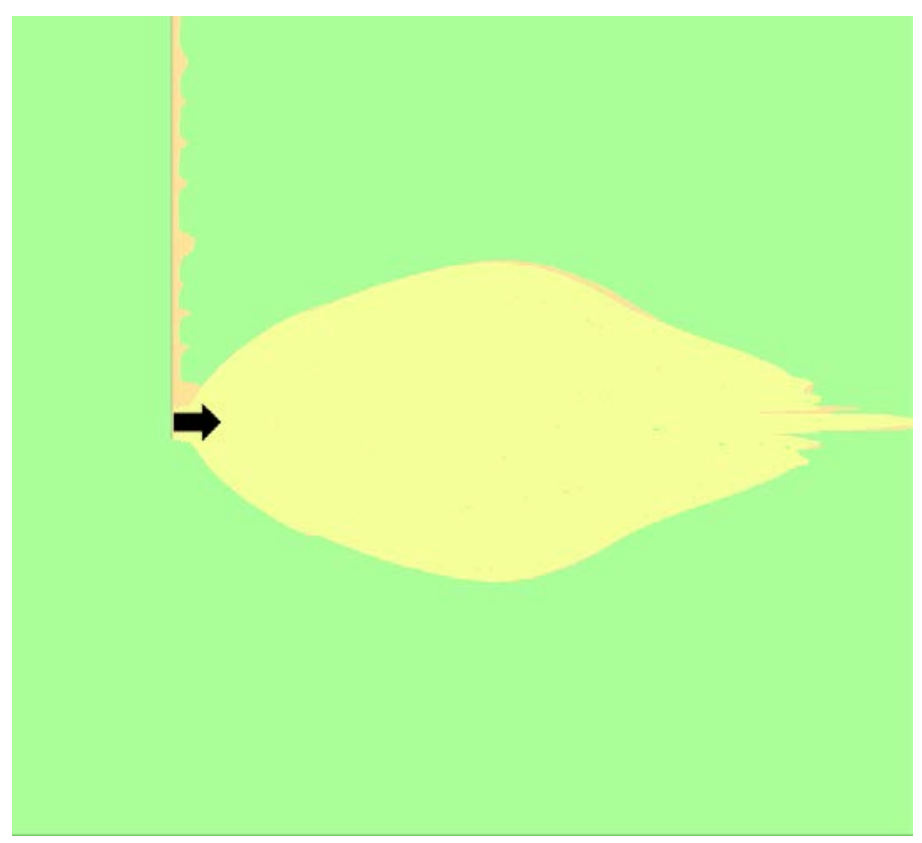

Figure 19. Vapor cloud (at or above $1 / 2-L F L$ concentration) for scenario LNG-3a (close sump) \& LNG-3b (remote sump), "Open field" unmitigated case.

Figure 19 shows the results of the unmitigated loading line release with a sump near the release point (LNG-3a shown in yellow), a sump remote of the release point (LNG-3b shown in orange). Evaporation from the liquid pool was calculated using a concrete substrate and the default thermal properties in FLACS. The results indicate that the overall footprint of the flammable vapor cloud has negligible dependence on the location of the collection sumps.

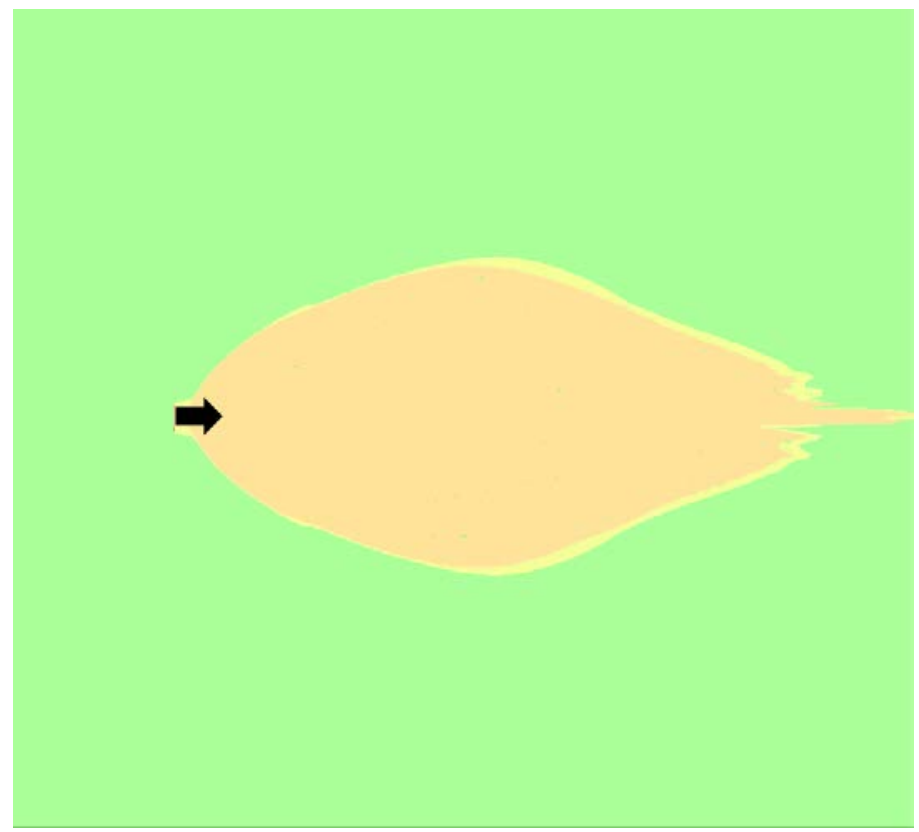


Figure 20. Vapor cloud (at or above 1/2-LFL concentration) for scenario LNG-3a (close sump) \& LNG-3c (vapor only), "Open field" unmitigated case.

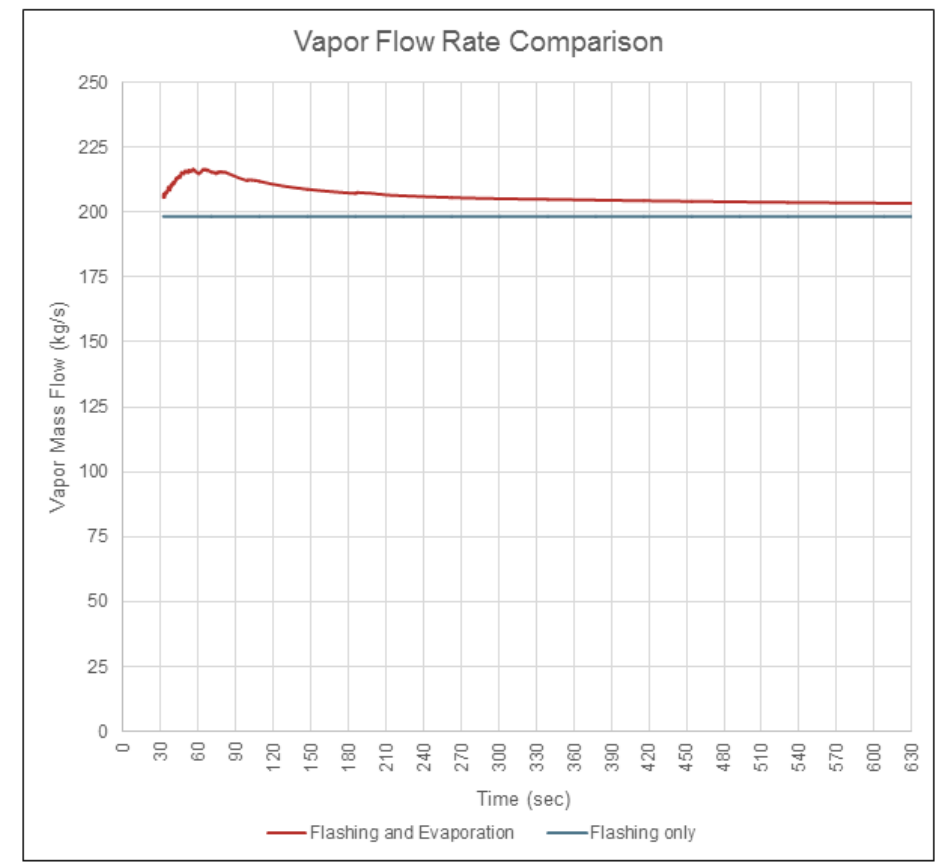

Figure 21. Vapor flow rate comparison with and without including the rainout fraction (and resultant evaporation from the liquid pool) for cases $L N G-3 a \& L N G-3 c$.

Figure 20 compares the cloud footprint for the release with a sump near the release point (LNG3a, again shown in yellow) and the same release neglecting the rainout fraction (LNG-3c shown in orange). While there is a slight difference in the width of the cloud footprint downwind of the release point, the furthest extent of the cloud is virtually unchanged. Figure 21 shows the vapor generation rates for the two cases presented in Figure 20. When the leak starts 30 seconds into the simulation, there is an increase in vapor generation from the liquid contacting the warmer concrete and evaporating. As the liquid pool begins to cool the concrete, the vapor generation rate decreases. Even though the liquid rainout flow rate is higher than the vapor flow rate from the pipe, the additional vapor generation from the liquid pool is a small fraction of the pressurized vapor release from the pipe. At its maximum, vapor generation from the liquid pool is only about $10 \%$ of the vapor fraction release.

As the presence of the liquid rainout has minimal impact on the overall cloud footprint, yet is burdensome to the simulation duration, rainout was neglected for the barrier study of the LNG loading line and scenario LNG-3c was used. The results of the LNG loading line releases are shown in Figure 22 through Figure 25. 


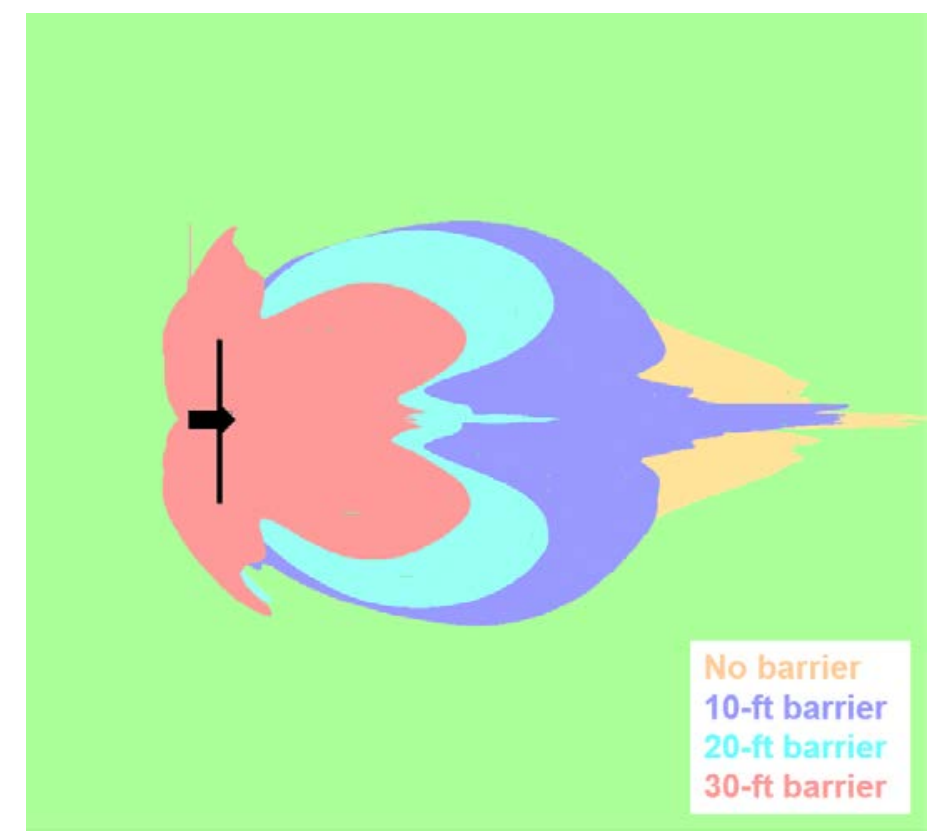

Figure 22. Vapor cloud (at or above ${ }^{1 / 2-L F L}$ concentration) for scenario $L N G-3 c$, "Internal 1 " barrier configuration.

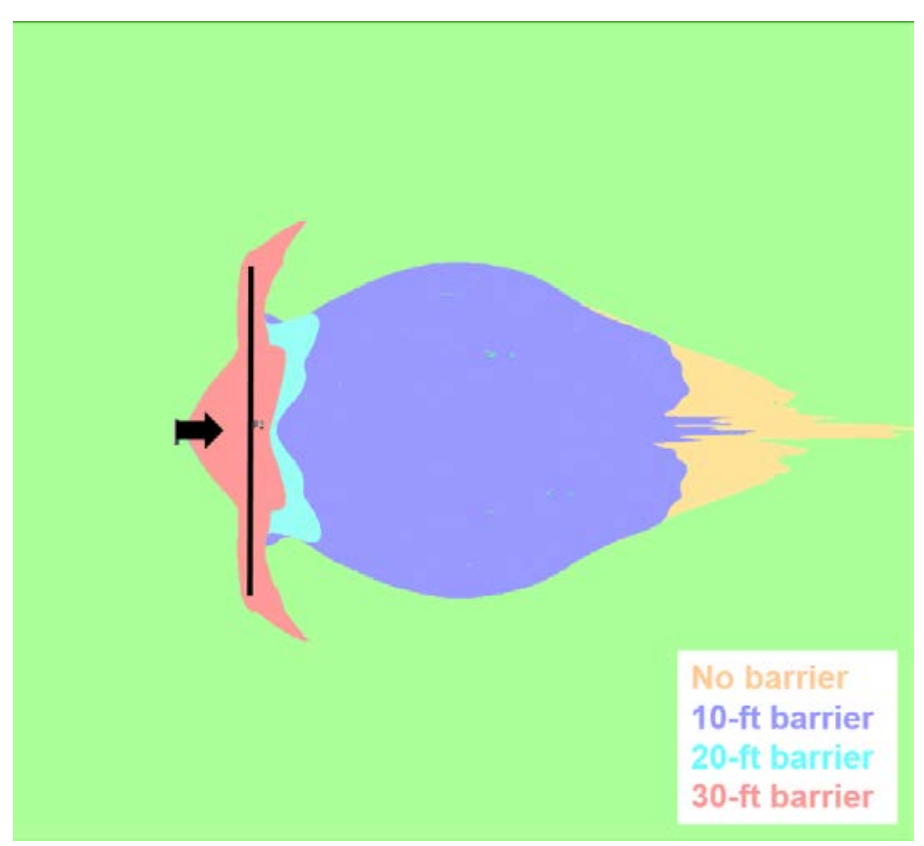

Figure 23. Vapor cloud (at or above $1 / 2-L F L$ concentration) for scenario $L N G-3 c$, "Internal 2" barrier configuration. 


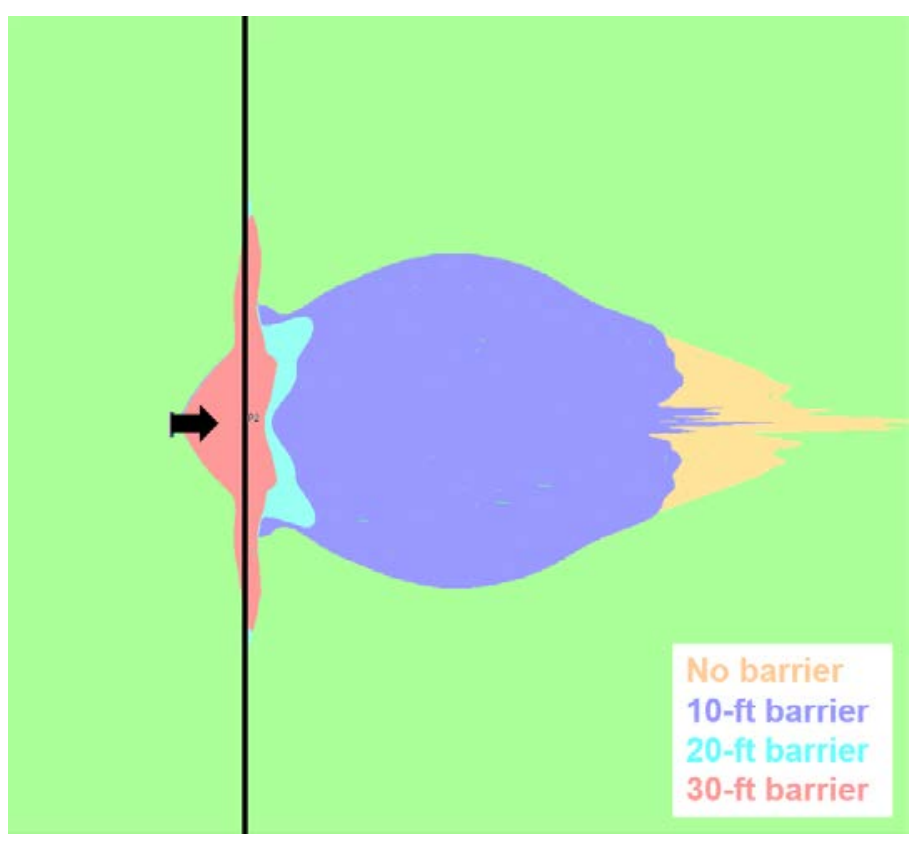

Figure 24. Vapor cloud (at or above $1 / 2-L F L$ concentration) for scenario LNG-3c, "Property 1 " barrier configuration.

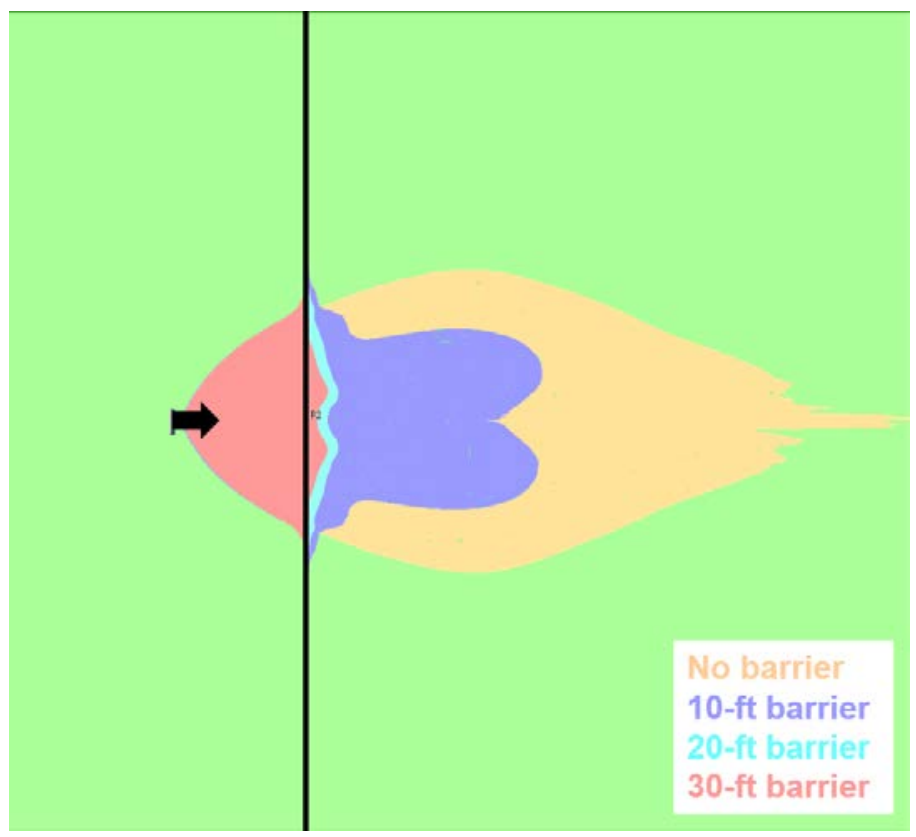

Figure 25. Vapor cloud (at or above 1/2-LFL concentration) for scenario LNG-3c, "Property 2" barrier configuration.

The closest barrier, Internal 1, continues to decrease in performance value as the release rate increases. Figure 22 shows very little reduction in the furthest extent of the cloud for the $10 \mathrm{ft}$ barrier case, and the 20 and $30 \mathrm{ft}$ barriers offer longer dispersion distances with the barrier at 150 $\mathrm{ft}$ than for the other barrier locations. The $10 \mathrm{ft}$ barrier only shows marked improvement for the 
$1000 \mathrm{ft}$ case, but the cloud still travels a significant distance after the barrier. The 20 and $30 \mathrm{ft}$ barriers perform similarly at the 500 and $1000 \mathrm{ft}$ distances, however, neither height would be sufficient as a property line barrier. A release of this magnitude often requires a combination of barriers at different locations or a very tall property line barrier.

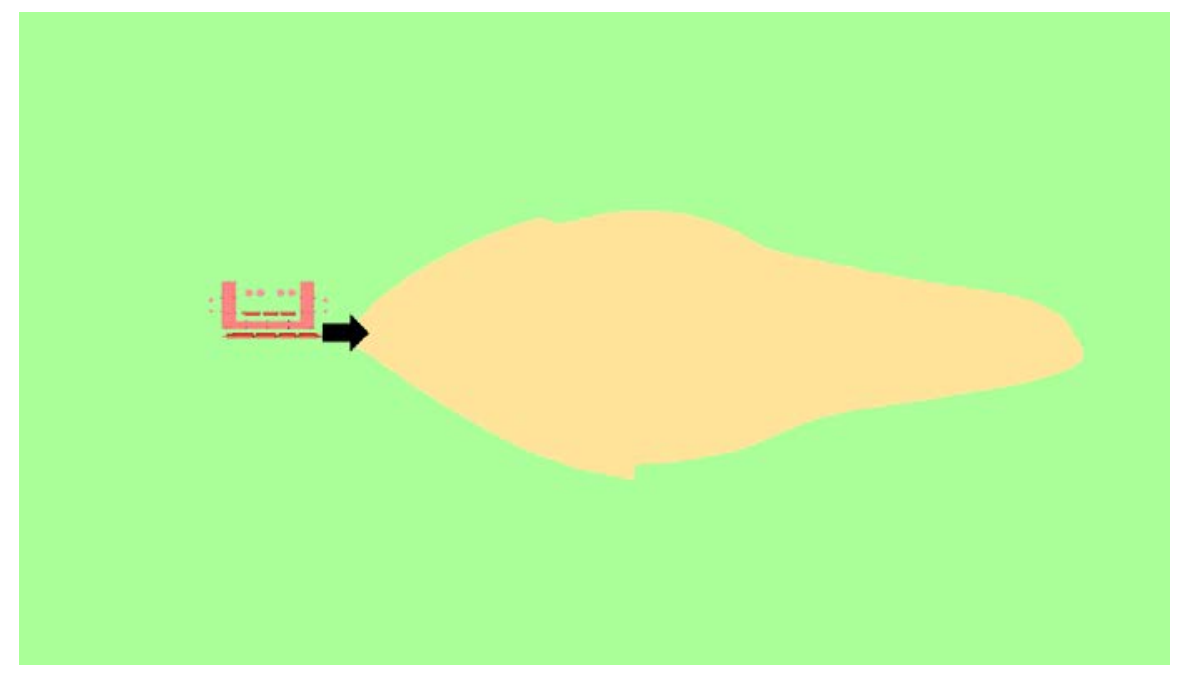

Figure 26. Vapor cloud (at or above $1 / 2-L F L$ concentration) for scenario PRO-1, “Open field” unmitigated case.

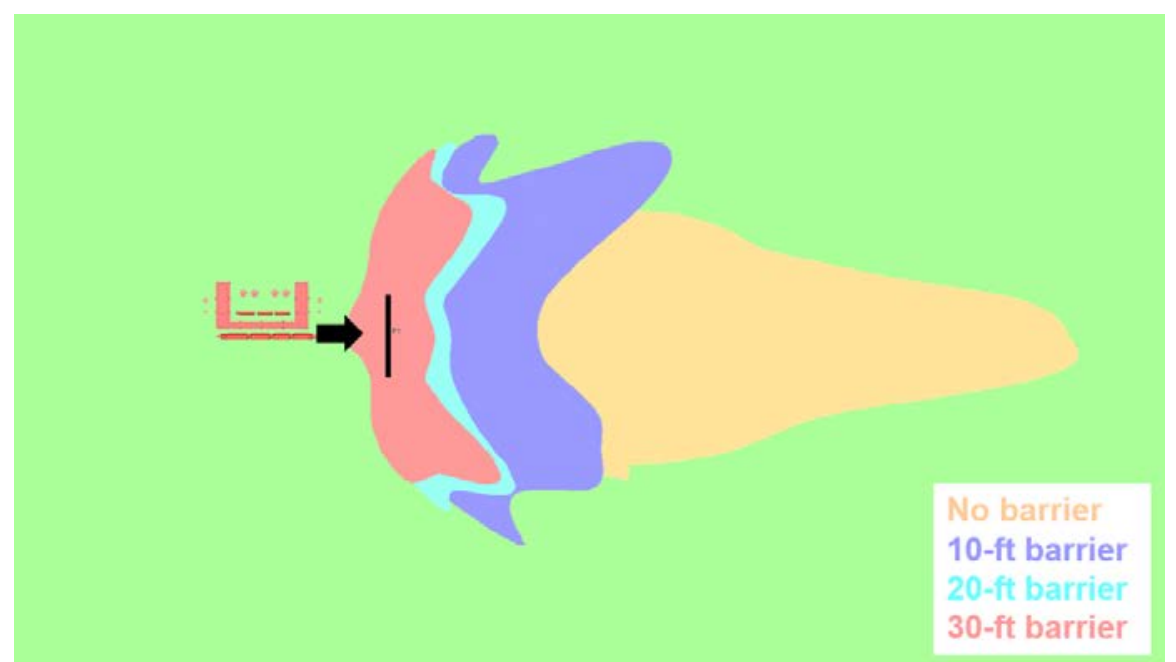

Figure 27. Vapor cloud (at or above 1/2-LFL concentration) for scenario PRO-1, “Internal 1" barrier configuration. 


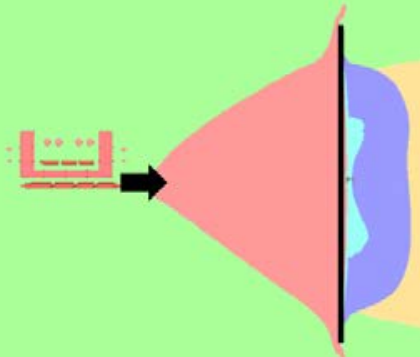

No barrier

10-ft barrier

20 -ft barrier

30 -ft barrier

Figure 28. Vapor cloud (at or above $1 / 2-L F L$ concentration) for scenario PRO-1, “Internal 2" barrier configuration.

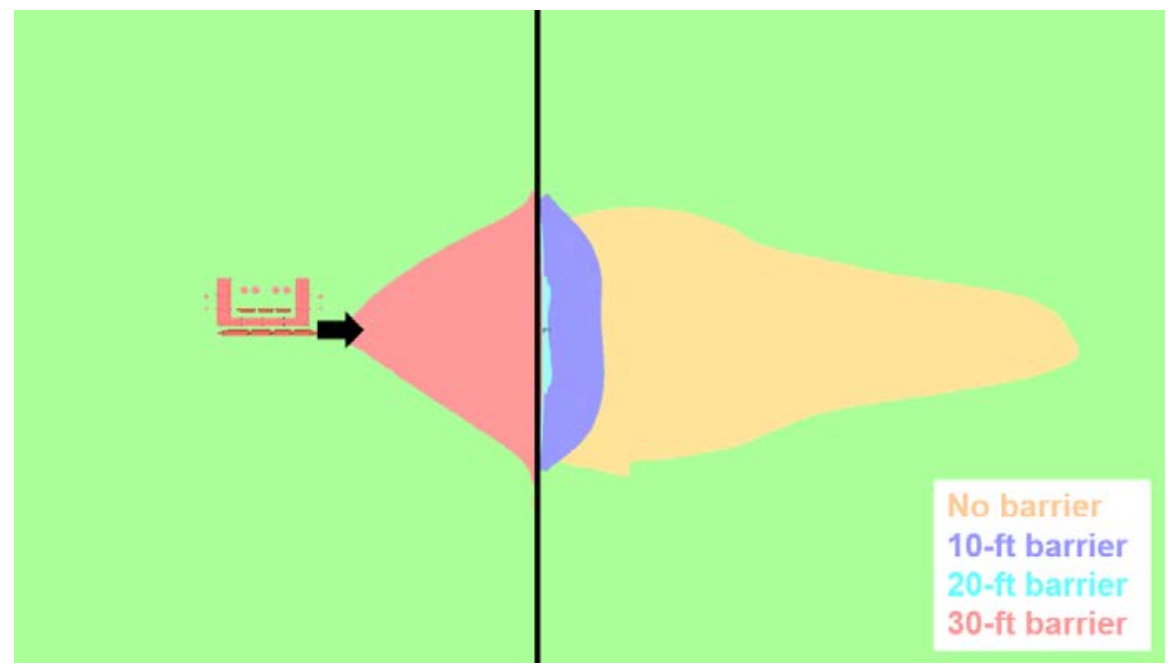

Figure 29. Vapor cloud (at or above $1 / 2-$ LFL concentration) for scenario PRO-1, “Property 1 ” barrier configuration. 


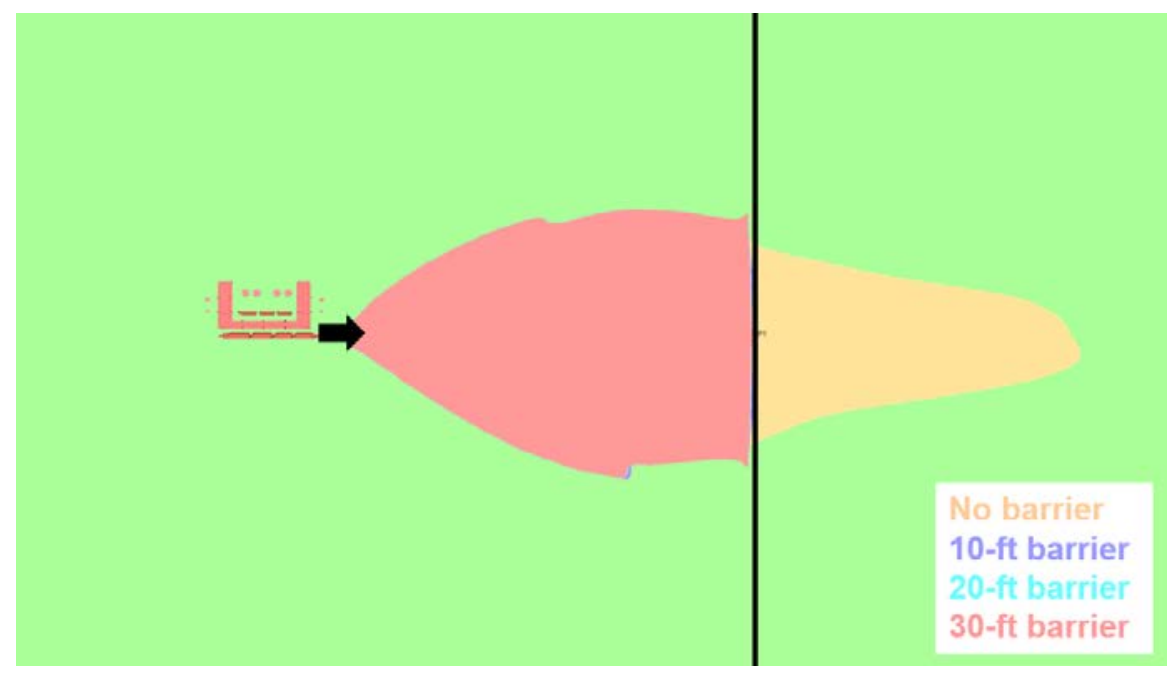

Figure 30. Vapor cloud (at or above $1 / 2-L F L$ concentration) for scenario PRO-1, "Property 2" barrier configuration.

The results for the propane release from the process area show that a $10 \mathrm{ft}$ high vapor barrier placed 150-500 ft from the release point will yield similar results in overall dispersion distance. The 20 and $30 \mathrm{ft}$ barriers were more effective at closer locations to the release point as their increased height reduced the clouds ability to go over the barrier, therefore slowing the momentum of the cloud and redirecting cloud spread laterally. The $1000 \mathrm{ft}$ barrier was far enough from the release that even the $10 \mathrm{ft}$ barrier was able to stop the advancement of the cloud front and increased barrier height added no benefit.

Figure 31. Vapor cloud (at or above 1/2-LFL concentration) for scenario PRO-2, “Open field" unmitigated case. 


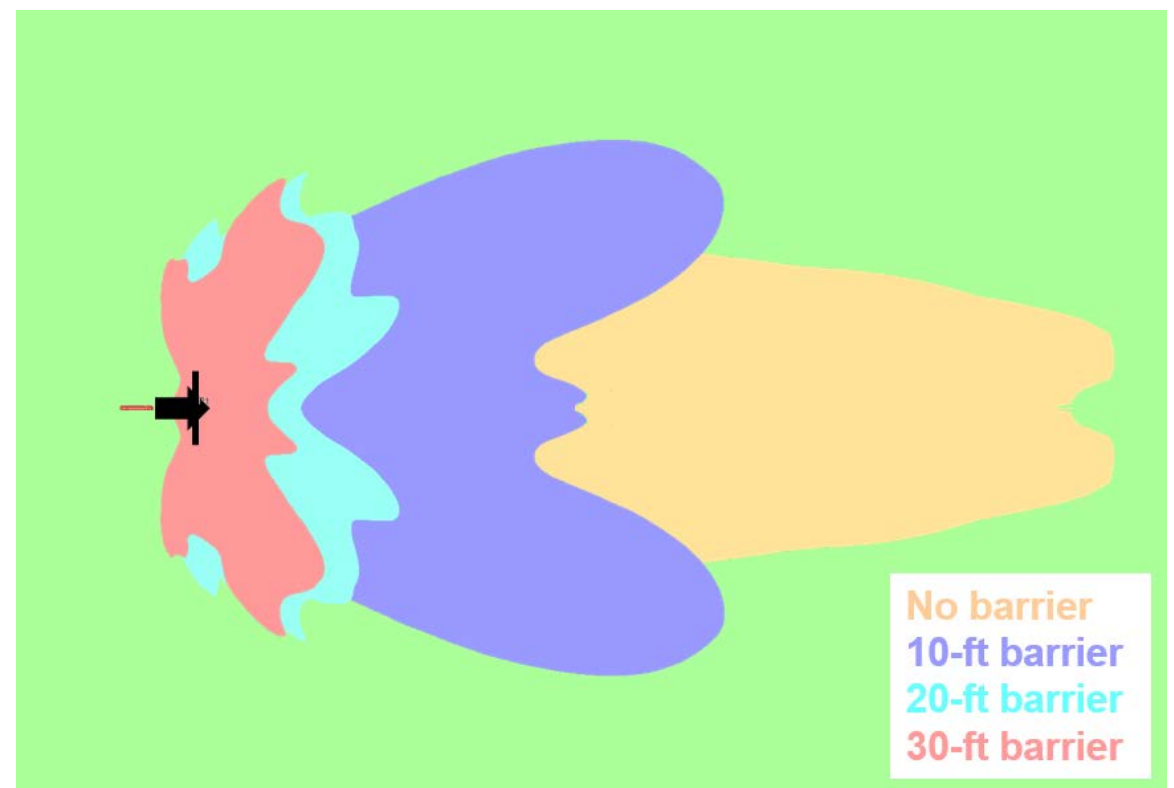

Figure 32. Vapor cloud (at or above $1 / 2-$ LFL concentration) for scenario PRO-2, “Internal 1" barrier configuration.

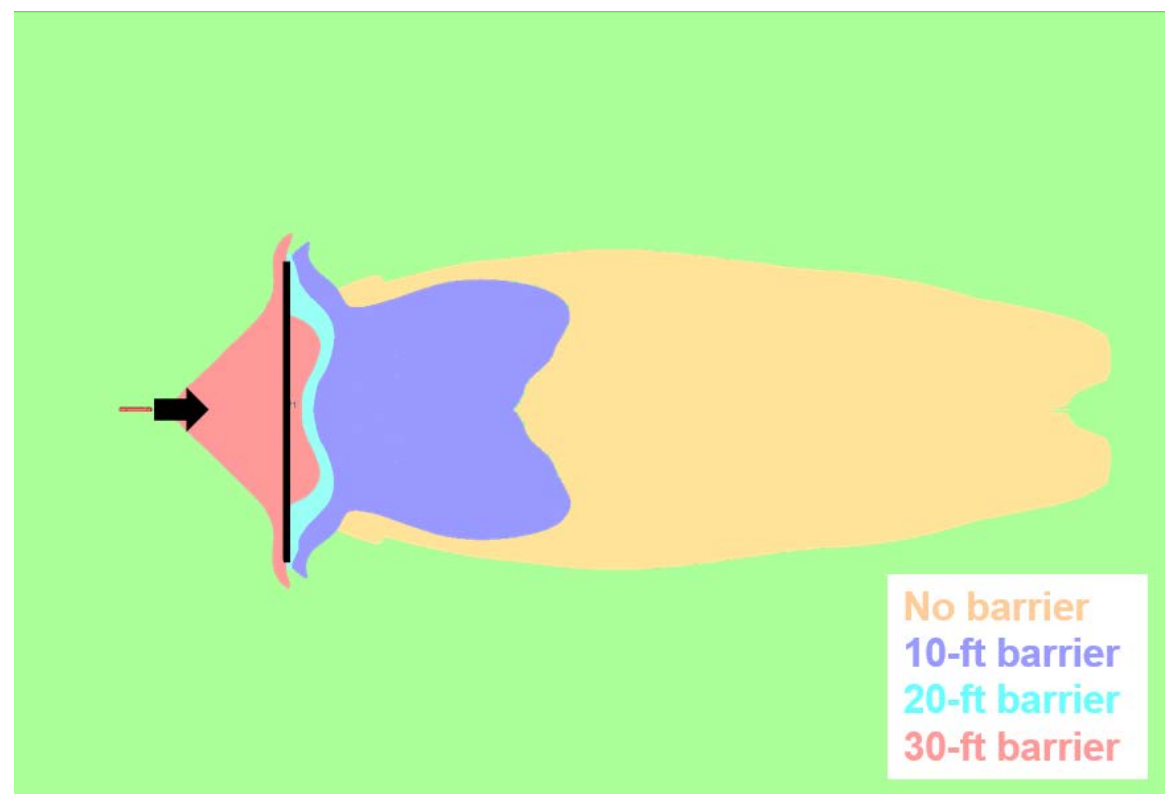

Figure 33. Vapor cloud (at or above 1/2-LFL concentration) for scenario PRO-2, “Internal 2" barrier configuration. 


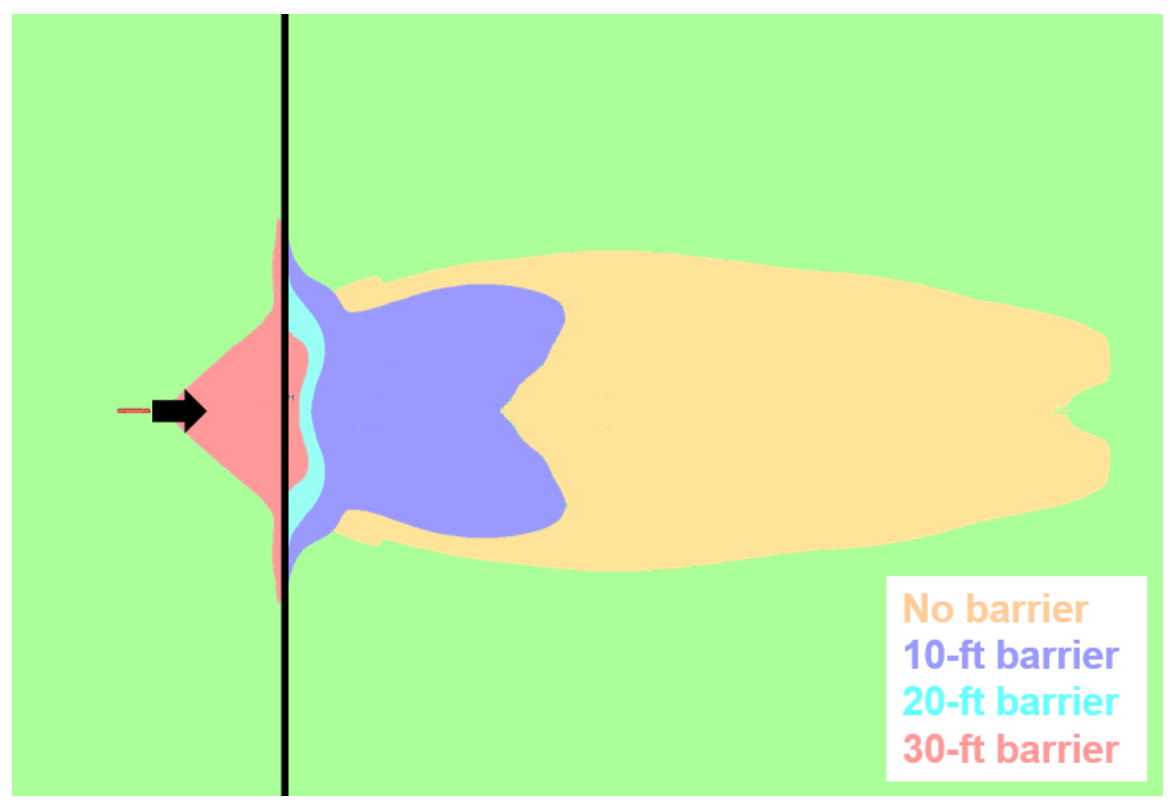

Figure 34. Vapor cloud (at or above $1 / 2-L F L$ concentration) for scenario PRO-2, "Property 1" barrier configuration.

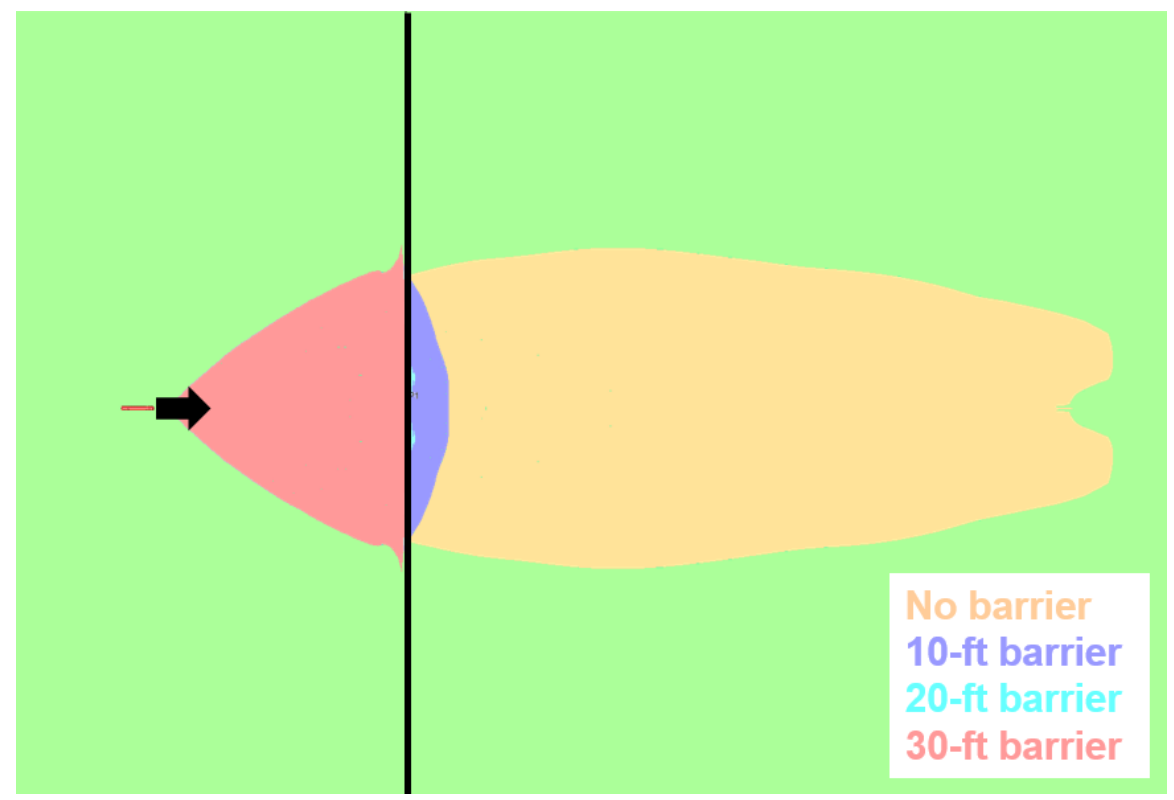

Figure 35. Vapor cloud (at or above $1 / 2-L F L$ concentration) for scenario PRO-2, "Property 2" barrier configuration.

The results show that for the higher propane flow rate the Internal 1 configuration is too close to the release to stop the momentum of the cloud unless the barrier at least $20 \mathrm{ft}$ tall. The $500 \mathrm{ft}$ barrier location was effective as an internal barrier to significantly reduce the furthest extent of the vapor cloud. However, if this release point were located $500 \mathrm{ft}$ or less from a property line, a barrier in excess of $30 \mathrm{ft}$ high would be required to fully contain the cloud. For a release located 
$1000 \mathrm{ft}$ from the nearest property line, a vapor barrier of at least $30 \mathrm{ft}$ would be required to contain the cloud in the absence of notable object density and congestion. The cloud barely gets over the $20 \mathrm{ft}$ high barrier at this location, suggesting that the presence of objects between the release and the property barrier and some topographical features could result in cloud containment.

\section{Conclusions}

The flammable vapor cloud footprints for releases of LNG and propane typically required for the siting of LNG facilities under US federal jurisdiction were presented to demonstrate the effect of different vapor barrier heights and locations. Vapor barrier performance for similar release rates was consistent between LNG and propane releases for barriers located $500 \mathrm{ft}$ or more from the release point, which indicates that the LNG clouds can remain negatively buoyant for long distances. Barriers located closer to the release were more effective for smaller releases (up to $50 \mathrm{~kg} / \mathrm{s}$ ); larger releases required progressively taller barriers in order to reduce the momentum of the cloud enough to redirect the cloud spread laterally. For barriers located $500 \mathrm{ft}$ downwind of the release, $10 \mathrm{ft}$ tall barriers were enough to reduce the cloud footprint, but were significantly less effective than the 20 and $30 \mathrm{ft}$ barriers, which often performed similarly. For small releases (up to $50 \mathrm{~kg} / \mathrm{s}$ ), 10-ft barriers located $1000 \mathrm{ft}$ downwind of the release point were able to contain the cloud; however, $30 \mathrm{ft}$ barriers were required to stop the cloud spread for releases up to 100 $\mathrm{kg} / \mathrm{s}$.

The large release rates associated with LNG transfer lines (such as scenario LNG-3) are difficult to contain with a single barrier. These releases often need to be mitigated with a combination of internal and property line barriers. Though these releases have significant rainout fractions, the vapor generation from evaporation of the liquid pool is a small fraction of the vapor generation rate. The modeling results demonstrated that neglecting the rainout fraction of the release provides a comparable flammable cloud to cases that include rainout. Therefore, neglecting rainout in the early stages of a vapor barrier optimization study could reduce simulation times.

All simulations were performed in an open field environment with flat terrain and no congestion. The presence of obstructions (e.g., plant equipment and buildings) and topography may reduce the overall dispersion of the flammable vapor clouds and thus may reduce the need for expensive mitigation measures; therefore, it is highly advisable to produce a detailed and accurate 3D representation of the facility and surrounding terrain. A wind speed of $2 \mathrm{~m} / \mathrm{s}$ was selected for this study, but depending on the weather data for a specific location, dispersion in $1 \mathrm{~m} / \mathrm{s}$ wind may be required which often yields longer dispersion distances. Future work to evaluate the impact of vapor barriers on the overall flammable cloud footprint would include sensitivities to congestion levels and lower wind speeds. The effects of staggered barriers at various distances and patterns also warrants evaluation, but the layout and performance of these barriers would be more heavily dependent on the layout and topography of a specific location. 


\section{Bibliography}

[1] Title 49, Federal Code of Regulations, Part 193 - Liquefied Natural Gas Facilities: Federal Safety Standards.

[2] B. Hjertager, "Computer simulation of turbulent reactive gas dynamics," Modeling, Identification and Control, no. 5, p. 211-236, 1985.

[3] F. \&. N. P. Harlow, "Turbulence transport equations," Physics of Fluids, no. 10, p. 23232332, 1967.

[4] B. \&. S. D. Launder, "The numerical computation of turbulent flows," Computer Methods in Applied Mechanics and Engineering, no. 3, pp. 269-289, 1974.

[5] S. Patankar, Numerical heat transfer and fluid flow, Taylor \& Francis, 1980.

[6] D. B. J. \&. v. W. K. Bjerketvedt, "Gas explosion handbook," Journal of Hazardous Materials, no. 52, pp. 1-150, 1997.

[7] S. H. O. \&. D. S. Hanna, "FLACS CFD air quality model performance evaluation with Kit Fox, MUST, Prairie Grass, and EMU observations," Atmospheric Environment, 2004.

[8] O. I. M. D. S. Hansen, "Validation of FLACS for Vapor Dispersion from LNG Spills: Model Evaluation Protocol," in Mary Kay O'Connor Process Safey Symposium, 2009.

[9] PHMSA FAQ, http://primis.phmsa.dot.gov/lng/faqs.htm. 